\title{
Bridging research and practice: Implementing and sustaining knowledge building in Hong Kong classrooms
}

\author{
Carol K. K. Chan
}

Received: 13 November 2010 / Accepted: 25 April 2011/

Published online: 5 June 2011

(C) The Author(s) 2011. This article is published with open access at Springerlink.com

\begin{abstract}
Despite major theoretical progress in computer-supported collaborative learning (CSCL), relatively less attention has been paid to the problem of how research advances may impact schools and classrooms. Given the global changes and educational policies for twenty-first century education, issues of how research in CSCL can be integrated with classroom practice for innovation pose important challenges. This paper draws on experiences in Hong Kong and examines research-based CSCL classroom innovations in the context of scaling up and sustaining a knowledge-building model in Hong Kong classrooms. It begins with an examination of the rationale for CSCL research in classrooms and then considers a range of problems and constraints for school implementation. Classroom innovations involve complex and emergent changes occurring at different levels of the educational system. The experience of CSCL knowledge-building classroom innovations in Hong Kong schools is reported, including: the macro-context of educational policies and educational reform, the meso-context of a knowledge-building teacher network, and the micro-context of knowledge-building design in classrooms. Three interacting themes - context and systemic change, capacity and community building, and innovation as inquiry - are proposed for examining collaboration and knowledge creation for classroom innovation.
\end{abstract}

Keywords Knowledge building $\cdot$ Educational practice $\cdot$ CSCL pedagogy $\cdot$ Teacher communities $\cdot$ Learning technology $\cdot$ Knowledge forum

\section{Introduction}

With the advent of knowledge-based societies, global educational reform movements now emphasize the need for twenty-first-century skills. How people collaborate for knowledge creation has become an important educational goal for productive citizenship. Computersupported collaborative learning (CSCL) is a maturing field with increasing breadth and

C. K. K. Chan $(\bowtie)$

Faculty of Education, The University of Hong Kong, Pokfulam, Hong Kong

e-mail: ckkchan@hku.hk 
depth in examining theory, method, pedagogy, and technology related to how collaboration and learning emerge when people work together (Stahl and Hesse 2010). While major theoretical progress has been made, the complex problem of how CSCL research can impact educational practice has received limited attention-success in CSCL research is not easily translated into classroom practice. CSCL research that examines collaboration among individuals, groups, communities, and organizations is well positioned to examine how CSCL approaches can be drivers for classroom innovations for knowledge advances and impacts on schooling.

Broadly speaking, the failure of educational research and technologies to alter the core practices of schools has been observed to be pervasive in educational reforms throughout the twentieth century, from the use of radio and television to the Internet (Cuban 1986; Cuban et al. 2001). More recently, the IEA SITES 2006 study reveals that, despite much investment and infrastructure growth, pedagogical orientations had not altered substantially when information and communication technologies (ICT) were introduced (Law et al. 2008). Researchers have noted that decades of funded research on exciting programs in technology-enhanced learning have not resulted in sustained or effective improvements to classroom practice (Sabelli and Dede 2000). The problem of how researcher-designed innovation can have sustained practice in classrooms has perplexed researchers in science and math education (Barab and Luehmann 2003; Roschelle et al 2008). This paper proposes that it is time to examine more directly questions of impacts of CSCL research, pedagogy, and tools on educational practice.

Over the past two decades, a wealth of theoretical perspectives has emerged in the fields of learning sciences and CSCL that posit learning as distributed, social, collective, and mediated by the use of tools (Bereiter 2002; Salomon 1997; Sfard 1998; Stahl 2006). There are a spectrum of theories and systems of analyses that examine how collaboration takes place with multi-vocal paradigms and approaches (Stahl et al. 2006). Various collaborativeinquiry-based approaches examine how students engage with complex problems, interact with others, and co-construct understanding supported by CSCL technology. Web-based learning has become more engaging and provides increased opportunities for interaction, while collaborative practice has increasingly characterized both formal and informal learning (Koschman et al. 2002). In the 1990s, there were focused efforts to bring insights of cognitive-science research to classroom practice (i.e., the Schools for Thought project; Goldman 2005); some researchers have examined the problem of scaling up (Dede and Honan 2005). Advances in design-based research are taking place that aim to bridge the gap between research and practice (Collins et al. 2004). With these developments, the gap between research and practice is still wide; it would be fruitful to build upon these advances to investigate how CSCL research can impact classroom practice for educational change.

Educational reform is a global phenomenon that is particularly active in the AsianPacific region. Since the education-school systems in Asian countries tend to be more centralized than their Western counterparts, their changing educational policy may be more aligned with research, and educational reforms may provide exciting opportunities for CSCL research to impact classroom practice. As such, some researchers in the AsianPacific region have initiated research projects using models of CSCL and learning sciences in close collaboration with schools and teachers, in some cases focusing on research for classroom innovation (Looi et al. 2011).

This paper explores issues and questions of CSCL research in classrooms through examining the experience of how knowledge building - a research model of CSCL-is implemented and scaled up in Hong Kong classrooms. Since 2000, the Hong Kong government has launched major initiatives to implement educational reforms that reflect 
twenty-first-century education and to support classroom innovations in schools. The experience of the knowledge-building innovation may highlight issues and questions for examining how CSCL can be integrated into classroom systems. This paper does not employ methods of detailed reporting of data collection and analyses; rather, it adopts a specific scientific genre that combines descriptive and narrative accounts with conceptual analyses supplemented with data to examine issues and questions related to the problem.

The paper begins by considering the need to examine CSCL research in classrooms and follows with analyses of problems and constraints. Educational change and classroom innovation are both complex, and it is useful to examine changes at different levels of the education ecological system (Resnick 2010). At the macro level, the case study begins with educational reforms and the policies of the Hong Kong government that provided a favorable context for CSCL classroom innovation. At the meso-level, its focus is on how a knowledge-building teacher network supported teacher change towards classroom innovation. The study also addresses the micro-level classroom design to illustrate how principles, pedagogy, and technology are integrated, considering the socio-cultural context, for example, the strong emphasis on examinations in Hong Kong schools. This paper proposes three interacting themes - context and systemic change, capacity and community building, and innovation as a process of inquiry - with which to examine issues and questions of how CSCL research may create innovation in classrooms. Specifically, this paper discusses efforts to create research-practice links and considers organizational challenges, capacity building, and pedagogical transformation with research implications for CSCL.

\section{Examining impacts of CSCL research in classrooms}

Changing global, technological, socio-economic, and educational contexts emphasize the importance of collaboration in a knowledge-based economy. In Asian countries and internationally, education-reform movements have emphasized the need to develop citizens' capacities for knowledge creation, inquiry, and collaboration, all of which are central to CSCL research. These needs are stated in educational research and policy documents produced by diverse bodies, such as the National Council of Teachers of Mathematics in the USA, the Organization for Economic Cooperation and Development, and various governments in Asian countries. Collaboration is pivotal to the advancement of knowledge and CSCL community can help to provide the knowledge needed to meet the demands of globalization and education in the twenty-first century.

An analysis of current work in CSCL, for example, indicates its interdisciplinary focus with diverse approaches, paradigms, and multi-vocality of analyses. CSCL research examines dialectics of both individual and collective cognition and modes of participation; it addresses various research themes including, to name a few, intersubjectivity, group cognition, scripting, argumentation, and knowledge building. CSCL practice ranges from dyads, small groups, classes in laboratories, classrooms, communities of practice, as well as through multi-institutional research. The interdisciplinary nature of the CSCL field makes it a rich ground for examining diverse approaches and theory-research-practice synergy.

As a key element of CSCL research is to examine how learning and collaboration emerge mediated by technology, discourse naturally becomes a key object of analysis. While advances are being made, currently, the bulk of CSCL research focuses on investigating micro-level analyses of discourse, mostly in small groups, rather than examining how complex emergent social structures may constrain or facilitate CSCL 
participation. Concerns have also been raised that the unit of analysis usually focuses on short durations (minutes) rather than on sustained periods of collaboration for knowledge production. Generally, CSCL research has given relatively less attention to conducting research in classroom settings.

These concerns suggest the need to examine the complex interplay and alignment of cognition, discourse, design, and context (or internal and external processes) in which CSCL pedagogy and tools are introduced. For CSCL tools to be effective, changes are needed in institutional practices, norms, and culture; reciprocally, changing those practices also requires a detailed understanding of student thinking. Dillenbourg et al. (2009) discuss the challenge of orchestrating and integrating CSCL activities into larger pedagogical scenarios and classroom practice. Hakkarainen (2009) critiques knowledge-building theory for focusing too much on the progress of ideas. He argues that it is difficult to implement knowledge building in schools because the dimension of knowledge-building practice is often neglected. From a socio-cultural perspective, Krange and Ludvigsen (2009) argue that interventions are not fixed entities and must be examined in relation to how students interpret schooling situated within historical, socio-cultural, and situated perspectives. A dialectical approach is needed to analyze how institutional settings and environments can affect the way CSCL tools are practiced and how meaning is constituted (Arnseth and Ludvigsen 2006). Analyses need to go beyond separate components to examining systemlevel properties, such as the use of activity theory to examine the dynamics of networked communities for school reforms (Rasmussen and Ludvigsen 2009).

Specifically, researchers have proposed supplementing micro-level analysis of group interactions to meso-level analysis of collaboration in classrooms, school settings, institutions, and networked communities (Jones et al. 2006). Meso-level forces and processes are not just organizational structure; they refer to relational properties with interaction dynamics situated in social settings for relating different properties and dynamics and can be examined to see how they mediate between macro-level influences such as policy context and micro-level group interaction processes. In the broader realms of theories of learning, researchers have discussed changing metaphors of learning in terms of knowledge acquisition, acculturation, and knowledge creation (Paavola et al. 2004). Questions exist as to how CSCL research may be extended from dyads and small groups to classrooms and knowledge-creating communities and to examine design and conditions facilitating collaboration in complex educational settings. Researching CSCL practice in classrooms and schools in productive ways requires inquiry into more powerful theories and analytic approaches.

It is a common belief that theoretical knowledge is created in lab-based studies before being applied in the real world, a view that perpetuates the theory-practice gap (Sabelli and Dede 2000). Much interest has been given to the notion of Pasteur's Quadrant (Stokes 1997), which includes basic, applied, classification, and user-inspired approaches. Stokes argues that user-inspired approaches are fruitful because they demand research into fundamental scientific problems that can address practice. In a similar vein, design research in education is important for understanding real-world problems (Collins et al. 2004). Through implementing innovative designs and through iterations of formative evaluation to shape those designs, theories of learning and collaboration can be refined in classrooms. Similarly, Bereiter and Scardamalia (2008) argue against the separation of basic research and applied research - they propose the idea of research-based innovation as a third type of research that aims to create innovation to advance research and design.

Accordingly, classrooms are not merely sites for implementing research results; they may become sites for knowledge creation. How CSCL research works in broader social and policy contexts for policy-research-practice synergy is an important question to address. 


\section{Problems and challenges of implementing CSCL research in classrooms}

One can easily recognize the many challenges limiting the impact of CSCL research on practice. Researchers often work on identifying some phenomena, assuming them to be general and leaving it to practitioners to apply their findings in classrooms (Sabelli and Dede 2000). Schoenfeld (2006) notes that there are no mechanisms to take lab-based ideas into practice. There have been advances made through research, but there are few infrastructures in which scholars can apply them; the need to develop a stable research base for classroom application is lacking. In fact, there are few rewards in universities for such research innovation.

It is also recognized that the wider implementation of CSCL and technology-enhanced experiments has been constrained at different levels involving organizational, pedagogical, and epistemological factors. Engeström et al. (2002) point out that there are various factors that make transforming schools very difficult, including the broader social, spatial, and temporal structures. Furthermore, there are problems with capacity gaps, and teachers need to buy into the innovation. Epistemological and cultural factors, such as student beliefs and the tradition of teachers working as individual professionals, are generally not congruent with research in learning sciences and CSCL. Organizational and school-level constraints make it very difficult for teachers to reflect collectively on their practices and engage in sustained expansive learning in CSCL environments.

Scalability, adapting a successful local innovation to other contexts while retaining its principles and effectiveness, is a significant barrier to research impacting school practice (Dede and Honan 2005). It is very difficult to scale up success from one education setting to another, particularly when the innovations involve the application of technology. For educational innovations to scale up, various dimensions need to be considered, including the breadth of use across classrooms, the depth of understanding, the sustainability of innovation, and the ability of teachers to shift, change, and refine the innovation (Dede and Honan 2005).

The above problems and challenges exist at different levels and are compounded by barriers to coordinate changes among these levels. From the macro-level, governmental ministry decisions for implementing a given pedagogy or innovation are often not based on research findings, let alone on the quality of the research. At the meso-level, there are few enabling frameworks or structures for productive collaboration among researchers and teachers. At the micro-level of day-to-day classroom operations, teachers tend to work alone; they are busy and have little time to try out new approaches. Moreover, students generally hold epistemological views that are not congruent with what is advocated in CSCL research. Specifically, the practical tools are limited and require surveying what is available, adapting it to the local conditions, setting up infrastructure, carrying out the missing research, adopting long-term approaches to training and supporting teachers, and affecting a cultural change of public expectations, understanding, and attitudes (Stahl, personal communication, 2009). The different cultures of research and practice, and the lack of conceptual and practical tools to coordinate changes, result in theory-practice gaps that are wide and enduring.

\section{Conceptual themes for examining research-practice gaps}

Given the complexity of organizational, social, pedagogical, epistemological, and practical constraints, it may be useful to consider innovations as interacting changes occurring at 
different levels and nested systems of an ecological system. As individuals and groups influence the people, communities, and institutions of ecology, they are, in turn, influenced by them. Various theoretical analyses have been made; for example, Dede (2006) depicts educational innovation as evolving ecological systems, similar to the adaptation of biological organisms; Lemke and Sabelli (2008) discuss how educational change can be examined as processes of a complex system, in which emergent properties and changes at one level lead to changes in other levels due to feedback loops inherent to the system.

In the area of educational research, curriculum theorists have examined different levels of interacting changes. For example, Doyle (1992) discusses three levels of change: institutional, referring to the intersection of society and culture; programmatic, referring to program-level changes in schools; and classroom-level changes, referring to how teachers and students interpret the curriculum. Cognitive science researchers working on school implementation have discussed the importance of designing for and examining changes at different levels and of making coordinated changes in classrooms, schools, and school districts (Resnick 2010).

Research on scaling up for success also provides insights into possible conceptual analytic tools. Fishman et al. (2004) discuss scaling up efforts for Learning Technology in Urban Schools and postulate a framework on bridging cultural, capacity, and management gaps. Goldman (2005) describes designing for educational improvement based on a decade of work on The Schools for Thought project and highlights three sets of principles pertaining to educational change, organization change, and individual change. Dede and Honan (2005), drawing from successful examples of scaling up, discuss four themes: coping with change, promoting ownership, building capacity, and effective decision making. For capacity building, a community of practice is an important strategy; for example, the Wide-scale Interactive Development of Educators facilitates teachers' professional development through constructivist pedagogies supported by internet technology (Wiske and Perkins 2005). Means and Penuel (2005) focus on inquiring into large-scale innovation and using evaluation data at multiple levels to inform and improve the process of innovation. Roschelle et al. (2008) demonstrate that it is possible to conduct experiments into scaling up for robustness when examining the overall effects of intervention, including similar or dissimilar effects and variability across different sites.

These theoretical analyses all suggest that designing for collaboration and educational innovation involves changes at different levels of the system that need to be coordinated. As such, the case of knowledge building innovation in Hong Kong will be examined at various levels: macro-level systems and processes including educational policies and reforms, evolving and enabling meso-level system of a teacher network, and micro-level dynamics of how individuals and groups in classrooms engage, interpret, and create new knowledge. The study's emphasis is on the meso and micro levels and the macro level will provide an important context.

\section{The macro context: Educational reforms and socio-cultural context in Hong Kong}

Educational change in the knowledge era is a global phenomenon, and it takes different forms in different countries around the world. While competitive examinations remain a defining feature of Asian school systems, there have been major educational policy shifts towards new education goals that are quite compatible with the visions of learning sciences and CSCL. Paradoxically, despite cutting-edge research advances, the educational policies in Western countries seem more inclined towards standardized testing and the monitoring of 
students' basic skills (e.g., no child left behind). The SITES study shows that, with the exception of Finland, countries with more centralized curricula reported more increases in student-centered pedagogy in ICT integration compared to their counterparts (Law et al. 2008). The case of Asian schools engaging in CSCL classroom innovation is of particular interest because, while changes are necessary to meet twenty-first-century education goals, teachers are still pressured to help students face competition and meet examination standards.

The Hong Kong government has undertaken major initiatives to support the development of twenty-first-century education. In September 2000, the Education Commission of Hong Kong published the document Learning to Learn-Learning for Life, formally launching a comprehensive reform of education in Hong Kong to ensure that students are prepared for the twenty-first century. The document specifies four key learning tasks or pillars - project learning, information technology, reading to learn, and moral and civics education. Educational policies and curriculum reforms over the last decade include such major initiatives as structural change to the years of schooling (New Secondary Senior Curriculum), a shift from highly specialized curricula to diverse subject choices, introduction of a new interdisciplinary Liberal Studies curriculum, and assessment reforms incorporating more formative elements and school-based assessments.

In the area of computer-supported learning, the Education Bureau (Ministry of Education) has developed three 5-year plans as strategies for the development of ICT in education since the 1990s. The first strategy, "Information Technology for Learning in a New Era: Five-year Strategy" (1998-2003), focused on four key components to transform school education from a teacher-centered approach to a learner-centered one: (a) access and connectivity, (b) teacher enablement, (c) curriculum and resource support, and (d) community-wide culture. This first 5year plan laid the foundation of establishing IT infrastructure in schools and training teachers in its use. However, it focused mainly on technology and paid limited attention to pedagogical practices in technology-enhanced learning.

The second strategy, "Empowering Learning and Teaching with Information Technology," launched in 2004, envisioned "turning schools into dynamic and interactive learning institutions, and fostering collaboration among schools, parents and the community." The notion of collaboration was mentioned more explicitly in this strategy. This 5-year plan consisted of several strategic goals, including the intent to "enable students to engage in empowering modes of learning which include collaboration, inquiry and production of knowledge" and plans to empower teachers by developing communities of practice.

Although there are admirable goals in the documents, the ongoing evaluation showed that schools were still dominated primarily by traditional pedagogical practices, so a third strategy was launched, "Right Technology at the Right Time for the Right Task," stating more explicitly that IT was to be integrated through pedagogical practices rather than simply through technology implementation. This strategy highlights the importance of using ICT at the right time and in the right place and of changing mindsets and practices in collaboration through technology. It also warns against techno-centric thinking, likening this to "jumping on the bandwagon without critically examining whether adopting a particular technology will genuinely improve learning outcomes" (The Third Strategy on IT in Education, 2007, p. 4). There is more realization that the critical barrier is how teachers may be able to integrate technology into their curriculum and pedagogy.

Although these ICT reform plans are not focused on CSCL per se, they provide the readiness for the development of CSCL by encouraging schools to engage in pedagogical and technological innovation. At a macro-level, the institutional context includes issues, discourses, and decisions on the interactions between society, culture, and schooling. While 
educational reforms are occurring worldwide, Hong Kong's education system may be one of the few that engages in major system revamping. The government has focused on new educational goals such as learning how to learn, collaboration, and technology skills to meet emergent societal needs. At the heart of Hong Kong government's educational vision for the twenty-first century is a desire to address pressing economic, social, cultural, and technological challenges through institutional changes.

As new education policy sets the stage, various factors facilitate changes for innovation, including top-down and bottom-up initiatives. Many Asian educational systems, including that of Hong Kong, have centralized curricula, and schools are required to follow changes outlined in reform documents. Teachers are expected to meet the requirements for technology competence and schools must engage in school-based reforms. To phase in these changes, school-based development initiatives are encouraged and a variety of seed projects have been developed within clusters of schools to encourage innovation. Funding opportunities exist for teacher buy-out time for new pedagogy and technology, and various schemes enable schools to collaborate with universities and the Education Bureau for teacher development. In addition, schools are encouraged to seek support for reform initiatives from the public, including various stakeholders and parental support. Strong political leadership during the time of educational policy reforms made these major changes possible.

The macro-context includes societal and institutional forces, as well as historical and cultural values and norms. It is a perplexing phenomenon that Asian students consistently score higher on international tests than do their Western counterparts; the most recent example of this are the PISA results. While these tests may not be addressing the kinds of deep collaborative thinking advocated in CSCL research, they nonetheless point to interesting questions. Various explanations have been proposed, including historicalphilosophical traditions and family norms that emphasize academic achievement. While embracing and initiating new notions of educational goals, government policies continue to stress public examinations and standards common among Asian societies. Although emphasizing both deep inquiry and standardized examination seems almost paradoxical, such reform efforts are designed so as not to contradict deeply ingrained cultural beliefs (macro- and micro-level processes interact). These underlying socio-cultural and historical beliefs will influence how new pedagogy and technology are interpreted when CSCL research is introduced into school practice.

Educational reforms are fraught with challenges. Despite efforts in policy documents, many initiatives in Hong Kong merely focus on sharing educational information and materials on Web portals. It is widely acknowledged that teachers seldom read curriculum guides, believing them to consist merely of clichés. Government policies and reforms may provide the facilitating macro-contexts and conditions, but the actual implementation of initiatives must come from schools and teacher communities; coordination across levels is needed. Schools are key venues in which teachers gather together to negotiate and interpret reform documents. Through technological advances and CSCL research, a new kind of structure, teacher network, may emerge as a type of meso-level structure to bridge government policy with capacity building and classroom implementation. Various teacher communities have emerged in Hong Kong, some spontaneously and some supported by the government and universities.

\section{The meso context: The Knowledge-Building Teacher Network}

The Knowledge Building Teacher Network (KBTN), which consists of more than 50 teachers funded by the Education Bureau since 2006, is an attempt to address new 
educational reform goals. Knowledge building, sometimes called knowledge creation, is one of the early models of CSCL that predates the advent of the World Wide Web (Scardamalia and Bereiter 1994). While knowledge building is a common theme in smallgroup-based research, Scardamalia and Bereiter focus on collective cognitive responsibility for knowledge creation in communities, arguing that children need to develop knowledgecreation capacity similar to that of members advancing new knowledge in scientific and scholarly communities (Bereiter 2002; Scardamalia and Bereiter 2006).

This model is particularly relevant when examining education reforms as it seeks to address prevalent school problems that usually focus on task completion, even with new pedagogy such as project learning. These researchers argue that even young children can improve, refine, and produce community knowledge needed for twenty-first-century education. In their model, knowledge-building discourse is mediated by Knowledge Forum ${ }^{\circledR}$, a computer-supported learning environment in which students collaboratively formulate problems, construct and improve ideas, and refine theories in pursuit of collective progress.

Since the 1990s, various research studies have been conducted in North America, Europe, and Asia examining knowledge-building theories, methods, pedagogy, and technology (e.g., Hakkarainen 2002; van Aalst and Chan 2007; see Special Issue, Scardamalia 2010; Zhang et al. 2009). With regard to developing research-practice synergy and impacts for educational innovation, the Knowledge Society Network, based at the University of Toronto, consists of researchers and practitioners from different countries working towards creating knowledge communities and networks (Hong et al. 2010). The Knowledge-Building Teacher Network in Hong Kong, which is linked to the international knowledge-building network, examines how the model of knowledge-building research can be implemented and scaled up in the Asian classroom context. The network has been funded in phase one (2006-2008) and phase two (2008-2011); this division also reflects the formative evaluation of and ongoing inquiry into improved design for implementing and scaling up knowledge-building innovation.

Phase one (2006-2008): Context and participants

The Knowledge-Building Teacher Network began in Hong Kong in 2006 with a teacher "secondment" scheme funded by the Education Bureau (Ministry of Education). Since 2001, knowledge-building research projects have been conducted in Hong Kong classrooms (Lai and Law 2006; Lee et al. 2006; van Aalst and Chan 2007). As is the case with most research, these projects investigated knowledge building in individual classrooms for short durations. In collaboration with the Centre for Information in Education, which provided strong technology and infrastructure support, the author developed a knowledgebuilding teacher network to examine teacher learning and to extend the knowledge-building model to a range of classrooms in Hong Kong.

Table 1 shows the overall picture of the teacher network over the 4 years. The initial network consisted of seven experienced teachers "seconded" from the Education Bureau. Within that year, there were more than 20 new teachers recruited from different subject areas (including science, humanities, languages) and different school levels (Grade 5-12, ages 10-17). The seconded teachers' salary was supported by the Education Bureau, with $50 \%$ release time, so they have time to work on the project. All of the first batch of seconded teachers had experience with knowledge building in their own classrooms - they were joined together as a group with release time to work with the university researchers to implement knowledge building in schools. The new teachers were recruited to join projects funded by the Education Bureau. With education reforms, schools are required to 
Table 1 Basic information of the Knowledge Building Teacher Network, 2006-2010

\begin{tabular}{|c|c|c|c|c|}
\hline & \multicolumn{2}{|c|}{$\begin{array}{l}\text { Phase one: teacher-secondment } \\
\text { scheme }\end{array}$} & \multicolumn{2}{|c|}{$\begin{array}{l}\text { Phase two: university-school } \\
\text { partnership scheme }\end{array}$} \\
\hline & $\begin{array}{l}\text { Year } 1 \\
(2006-07)\end{array}$ & $\begin{array}{l}\text { Year } 2 \\
(2007-08)\end{array}$ & $\begin{array}{l}\text { Year } 3 \\
(2008-09)\end{array}$ & $\begin{array}{l}\text { Year } 4 \\
(2009-10)\end{array}$ \\
\hline Number of participating schools & 18 & 26 & 25 & 29 \\
\hline Primary schools & 5 & 7 & 11 & 12 \\
\hline Secondary Schools & 13 & 19 & 14 & 17 \\
\hline Participating teachers & $25-30$ & $40-50$ & $50-60$ & $50-60$ \\
\hline Seconded teachers & 7 & 6 & 6 & 6 \\
\hline Teacher associates & & & 6 & 9 \\
\hline Curriculum areas & \multicolumn{4}{|c|}{$\begin{array}{l}\text { Primary science, integrated science, chemistry, physics, biology, } \\
\text { geography, history, Chinese, English, liberal studies, mathematics, } \\
\text { design and technology }\end{array}$} \\
\hline
\end{tabular}

participate in pedagogical and technological innovation projects. School principals would choose from different projects supported by the Education Bureau, and they recommend their teachers to participate; KBTN is one amongst other projects. While the government support provides access to research sites, other sources of research funds make it possible for undertaking policy-research-practice integration. Multiple sets of data were collected, including student discourse on forums, domain tests and questionnaires, teacher discourse in meetings and workshops, teacher interviews, teacher artifacts, and classroom observation. As the focus of the paper is on the conceptual analysis of classroom practice of CSCL, data analyses will not be exhaustive, but highlights are included for illustrative purposes.

Phase one (2006-2008): Design and reflection on teacher collaboration

The first batch of seconded teachers worked closely with the researchers setting up the initial structure of the network. Setting up the infrastructure to bridge different levels and contexts turned out to be a highly complex task. In the initial phase, much time was spent on building basic infrastructures, teacher scheduling, needs identification, resource allocation, setting up technology, and inter-group liaisons. Early teacher discussions mainly focused on administration, task allocation, resource needs, scheduling, and division of labor and role assignment. There was also much negotiation as researchers and teachers sought to define their new roles as co-inquirers and to work with different cultural norms and expectations.

Another challenge was to support multiple classes using Knowledge Forum. Typically, Knowledge Forum databases are designed for individual classes or for several classes within a single school; now, however, the program needs to accommodate a network of 30 to 40 classes in a variety of schools. Teachers and researchers decided to allow crossfertilization among network teachers while maintaining technical feasibility and pedagogical goals. Using the affordance of multiple views and links, the platform was designed to allow teachers in different schools to work together and to have access to other classroom communities. The database in year 1 with many classes turned out to create many technology problems that were gradually improved over the next few years. In later years, 
teachers from different schools sharing similar curriculum areas and grade levels and inquiry topics were joined together and that facilitated the growth of sub-communities.

Teacher development activities included the following: The seconded teachers and researchers met weekly to act as a design team to design and improve knowledge-building practices in their own classrooms, share their understanding with their colleagues in their own schools, and provide peer coaching to other new teachers in the teacher network. Halftime release enabled the seconded teachers to stay in classrooms to extend their work and work collaboratively with their colleagues; they also needed to support new teachers through regular school and classroom visits and sharing their work on Knowledge Forum.

At the weekly meetings, the seconded teachers planned workshops, designed curriculum materials, and outlined instructional tasks. A teacher database was set up, which was used mostly as a clearinghouse for teacher materials. Although there were strong teachers in the group, it was quite challenging for them to work together: there were different viewpoints and some participants were resistant to new ideas. Furthermore, the initial underlying belief - that good knowledge-building teachers would be able to share their experience and help new teachers to learn - was found to be simplistic. While these experienced teachers advocated deep inquiry in the classroom, they often resorted to telling their peer teachers what to do in their classroom or making the Knowledge Forum views for them rather than engaging newcomers in reflection or scaffolding their understanding.

There were many failed attempts and false starts with iterative efforts while interesting lessons were learned. Although Knowledge Forum is usually included at the start of knowledge building in Canadian classrooms, it was not quite possible for the KBTN teachers. The new teachers who were first introduced to Knowledge Forum tended to focus on the tool itself and used the forum as a technology-based venue merely for teacherdirected instruction (e.g., posting questions as assignments). This observation showed us that teachers needed to change their mindsets and understand that their students can work together to build knowledge. These unsuccessful starts led to emergent changes with the teacher-researcher design of the knowledge-building pedagogy model (described in a later section), which includes an initial phase of acculturating students to a collaborative culture before introducing Knowledge Forum.

\section{Phase one (2006-2008): Analysis and ongoing evaluation}

Analysis was undertaken as feedback to the innovation in classroom and the teacher network. As discussed before, the project started with seven seconded teachers; these experienced teachers played a key role in recruiting new teachers to join the network through ministry-university-school joint events. By the end of year 2, there were more than 40 participating teachers. There were other teachers who had attended the network activities; but only those who were active enough to have conducted Knowledge Forum work were counted. There were many teachers attending the network activities with many fluctuations in sustained involvement.

\section{Student participation in Knowledge Forum}

While there was growth in the number of teachers, the participation patterns and quality of discourse in Knowledge Forum varied greatly. Analyses of forum notes indicated that some new teachers were setting up questions on the forum for students to respond mainly as answers to teacher questions (assignments). This phenomenon seems similar to what Brown and Campione (1996) characterize as a "lethal mutation" in classroom innovation; they 
coined the term to describe the problem of teachers superficially copying surface procedures but neglecting and thereby contradicting the principles. It seems that these KBTN teachers were assimilating the new knowledge-building model and fitting it into something with which they were familiar. Furthermore, many students were engaged in sharing opinions or information, or what has been called the knowledge-sharing discourse rather than collaborating for knowledge construction (van Aalst 2009).

\section{Examining student and teacher beliefs}

Analyses were conducted to examine what might contribute to different levels of participation, and a brief summary is reported here. Interviews with 23 network teachers were conducted to gain insights into their beliefs about knowledge-building practice. When asked about their goals, analyses suggest that some teachers focused on the technical aspects, as if classroom innovation were just about using a new piece of software. One teacher said:

"What do I think I can do to improve my knowledge-building practice next year? If your project provided me a $\mathrm{CD}$ or guides on how these Knowledge Forum functions work, I will learn them this summer and I think I can be much better next year." (Interview with a teacher, TCA)

Other teachers focused on the pedagogy and activity structures used in knowledge building. Here is an example:

"When planning for knowledge building in my classroom, my goal is to know more about pedagogy and curriculum designs of knowledge building. I do have concerns about the worksheets used currently in my school.... I hope we can develop better materials for class activities." (Interview with a teacher, TYC)

Some of the teachers, however, reflected on how knowledge building principles influenced the ways they view their classroom work. One teacher said:

"Unlike my mentor who can articulate the set of principles and I can't, [my goal] is that...I will try to use these principles to remind myself.... Sometimes when I asked my students to do certain work, I may doubt if that would work [out]. Then I think about some of these principles and remind myself that if community growth is possible... students may indeed be able to develop new knowledge when they work together." (Interview with a teacher, TTH) (italics for emphasis)

Further ongoing analyses show that the students of teachers with more principle-based views change more towards the view of collaboration that aligns with idea improvement and collective growth (Chan et al. 2008). Other analyses were also conducted. Student beliefs were examined using a questionnaire designed to tap into their views of collaboration as aligned with the knowledge-building perspective, the results of which showed that those students whose beliefs were more aligned with knowledge building had more productive participation patterns on Knowledge Forum (Chan and Chan 2011). The ongoing analysis and inquiry into student participation patterns on Knowledge Forum and teacher understanding provides some background for designing the teacher networkprimarily, it points to the importance of focusing on principles and more efforts to understand students' collaborative discourse. With the emphasis on continual inquiry for innovation, the teacher network underwent continual change. 
Phase two (2008-2010): Context and participants

Over time, the network's infrastructure has become more established, with better links across multiple levels, including ongoing liaison with the Education Bureau. As the number of teachers involved increased, the network received further government funding. After 2 years, in addition to seconded teachers (50\% release time), the project now includes "teacher associates," a group that includes seconded teachers who finished their term but sustained their practice and new teachers who have become active participants to spread the innovation. In year 4, the number grew to six seconded teachers and nine teacher associates. The number of teachers has fluctuated; but there were more than 50 teachers participating.

Phase two (2008-2010): Designing for teacher collaboration and knowledge building

The goal of the design is to help network teachers develop some integral understanding of principles, pedagogy, and technology as they experience knowledge building. Table 2 shows the overall design including network activities and three key themes on community building, principle-based understanding, and technology-enhanced inquiry.

Primarily, the network activities include (a) design meetings among researchers and seconded teachers/teacher associates, (b) subject area and school-based meetings led by seconded teachers/teacher associates for new teachers, (c) classroom visits for implementing knowledge building and open classrooms, (d) network-wide university-based workshops, (e) summer institutes and collaboration with international communities, (f) technology-based meetings for tool development with network teachers, and (g) dissemination seminars for the public. Amongst these activities, the weekly design meetings were developed as key sites of inquiry, collaboration, and knowledge creationthe strategy was to develop seconded teachers and teacher associates as teacher leaders who would then spread the innovation to other teachers. Furthermore, the university-based teacher workshops provide the venue for network teachers to experience knowledge building and writing on Knowledge Forum. As an example, network teachers put forth their ideas and questions, adapting the notion of the knowledge-building wall, and these ideas are further inquired and elaborated on a teacher database (Fig. 1). In the following subsections, the three key themes are described.

\section{Principle-based design and understanding}

Evaluations of phase one show that some network teachers merely worked on surface procedures, but those who focused on principles showed a deeper understanding. Various approaches were employed to help teachers move towards principles in their classroom implementation, for example, discussion of classroom and computersupported discourse were conducted from the lens of principles, teachers interpreting principles with other peer teachers, and teachers working with their students in developing their sets of principles.

Typically, during the design meetings, one or two seconded teachers would present an artifact from their teaching-e.g., a video clip, a selection of computer notes, or some artifacts. A knowledge-building group discourse would ensue, generating questions and explanations, much as their students experience in their knowledge-building discourses. For example, this discussion followed the viewing of a video clip of a classroom discourse presented by a seconded teacher. 
Table 2 Designing for teachers' knowledge building in the teacher network

\begin{tabular}{llll}
\hline Network activities & $\begin{array}{l}\text { Teacher-researcher } \\
\text { collaboration and } \\
\text { community building }\end{array}$ & $\begin{array}{l}\text { Principle-based design } \\
\text { and understanding }\end{array}$ & $\begin{array}{l}\text { Technology-enhanced } \\
\text { inquiry }\end{array}$ \\
\hline
\end{tabular}

\begin{tabular}{l}
\hline \\
Design meetings on \\
classroom work and \\
teacher professional \\
development
\end{tabular}

\section{Subject area and school-based teacher workshops}

\section{Classroom visits and open classrooms}

Researchers work with
seconded teachers
(ST) and teacher
associates (TA) in
addressing common
problems of
understanding
Hybrid culture of
teacher-researcher
co-inquiry and teach-
ers empowering
teachers

ST and TA as leaders in school-based workshops for network teachers; multiple zones of proximal development

ST and TA co-teach with new teachers based on curriculum designed in schoolbased workshops

Multiple and emerging groupings; shared goals and social practice

Network teachers, ST, $\mathrm{TA}$, researchers, and occasional visitors of students and ministry personnel working towards symmetrical advances

\section{ST and TA present classroom events and artifacts examined with principles}

\section{Explicit focus on student discourse and analyses informed with principles}

Collective effort to understand knowledge-building principles in light of student work

ST and TA adapt selected principles making them accessible to new teachers

ST and TA co-design curriculum with new teachers and model knowledge-building practices

Teachers reflect on classroom practice (e.g., KB talk) using principles

Classroom supportdebriefing and scaffolding using principles

Experienced ST and TA open their classrooms for visits; develop artifacts informed with principles

Workshops designed based on classroom problems informed with principles (e.g., student agency)

\section{Multiple and connected Knowledge Forum databases for all participating classroom communities}

\section{A Knowledge Forum teacher database to support teacher collective inquiry as a knowledge creation space}

Multiple databases for cross-fertilization and joint classroom work

Video recording and analyses to scaffold classroom practice

Suite of assessment tools including ATK and Applets for formative assessment

Resource Web with teachers co-designing collective artifacts 
Table 2 (continued)

\begin{tabular}{|c|c|c|c|}
\hline Network activities & $\begin{array}{l}\text { Teacher-researcher } \\
\text { collaboration and } \\
\text { community building }\end{array}$ & $\begin{array}{l}\text { Principle-based design } \\
\text { and understanding }\end{array}$ & $\begin{array}{l}\text { Technology-enhanced } \\
\text { inquiry }\end{array}$ \\
\hline & & $\begin{array}{l}\text { Knowledge-building } \\
\text { principles put forth as } \\
\text { objects of inquiry in } \\
\text { teacher online and } \\
\text { offline discourse; } \\
\text { emulate the process of } \\
\text { knowledge building }\end{array}$ & $\begin{array}{l}\text { A Knowledge Forum } \\
\text { Teacher database and } \\
\text { assessment tools }\end{array}$ \\
\hline \multirow[t]{2}{*}{$\begin{array}{l}\text { Collaboration with } \\
\text { international } \\
\text { communities }\end{array}$} & \multirow[t]{2}{*}{$\begin{array}{l}\text { Network teachers } \\
\text { working with } \\
\text { knowledge-building } \\
\text { teachers in other } \\
\text { countries; connection } \\
\text { with international } \\
\text { communities at uni- } \\
\text { versities; networks of } \\
\text { networks }\end{array}$} & $\begin{array}{l}\text { Teachers work on joint } \\
\text { student databases } \\
\text { using principles to } \\
\text { design the curriculum }\end{array}$ & $\begin{array}{l}\text { Knowledge Forum } \\
\text { joint databases across } \\
\text { communities }\end{array}$ \\
\hline & & $\begin{array}{l}\text { Attend Summer } \\
\text { Institute at University } \\
\text { of Toronto to enrich } \\
\text { their understanding of } \\
\text { principles }\end{array}$ & $\begin{array}{l}\text { Virtual conferences } \\
\text { among international } \\
\text { communities }\end{array}$ \\
\hline \multirow[t]{2}{*}{$\begin{array}{l}\text { Technology-based } \\
\text { meetings for tool } \\
\text { development }\end{array}$} & \multirow[t]{2}{*}{$\begin{array}{l}\text { Researchers, engineers, } \\
\text { graduate students, ST, } \\
\text { and TA working toward } \\
\text { a tool-design-research } \\
\text { community }\end{array}$} & $\begin{array}{l}\text { Technology design } \\
\text { linked to principles } \\
\text { and classroom needs; } \\
\text { tools to be employed } \\
\text { by teachers and } \\
\text { students for agency }\end{array}$ & $\begin{array}{l}\text { Technology-based } \\
\text { assessment tools and } \\
\text { ongoing development } \\
\text { for research-practice } \\
\text { synergy }\end{array}$ \\
\hline & & $\begin{array}{l}\text { Teachers, researchers, } \\
\text { and technical team } \\
\text { work collectively; } \\
\text { researchers design } \\
\text { tools for teacher } \\
\text { needs; teachers } \\
\text { provide contextual } \\
\text { information to } \\
\text { enhance tool design }\end{array}$ & \\
\hline Dissemination seminars & $\begin{array}{l}\text { Education Bureau, } \\
\text { schools, parents, and } \\
\text { public; connection } \\
\text { with stakeholders and } \\
\text { school community for } \\
\text { sustained innovation }\end{array}$ & $\begin{array}{l}\text { KBTN sharing } \\
\text { advances in } \\
\text { knowledge-building } \\
\text { practices with possi- } \\
\text { ble feedback to min- } \\
\text { istry policy for future } \\
\text { direction }\end{array}$ & $\begin{array}{l}\text { KBTN Web resource } \\
\text { portal open to school } \\
\text { communities }\end{array}$ \\
\hline
\end{tabular}

Teacher B: I am wondering how their discussion can be related to our problem of assessment? (\#1)

Teacher H: Um...I wonder... as students' ideas are continually improving, is it possible for students to reflect on what they thought at the beginning... what they... thought later... and um maybe they can even think about how they have deepened their ideas? (\#2) 

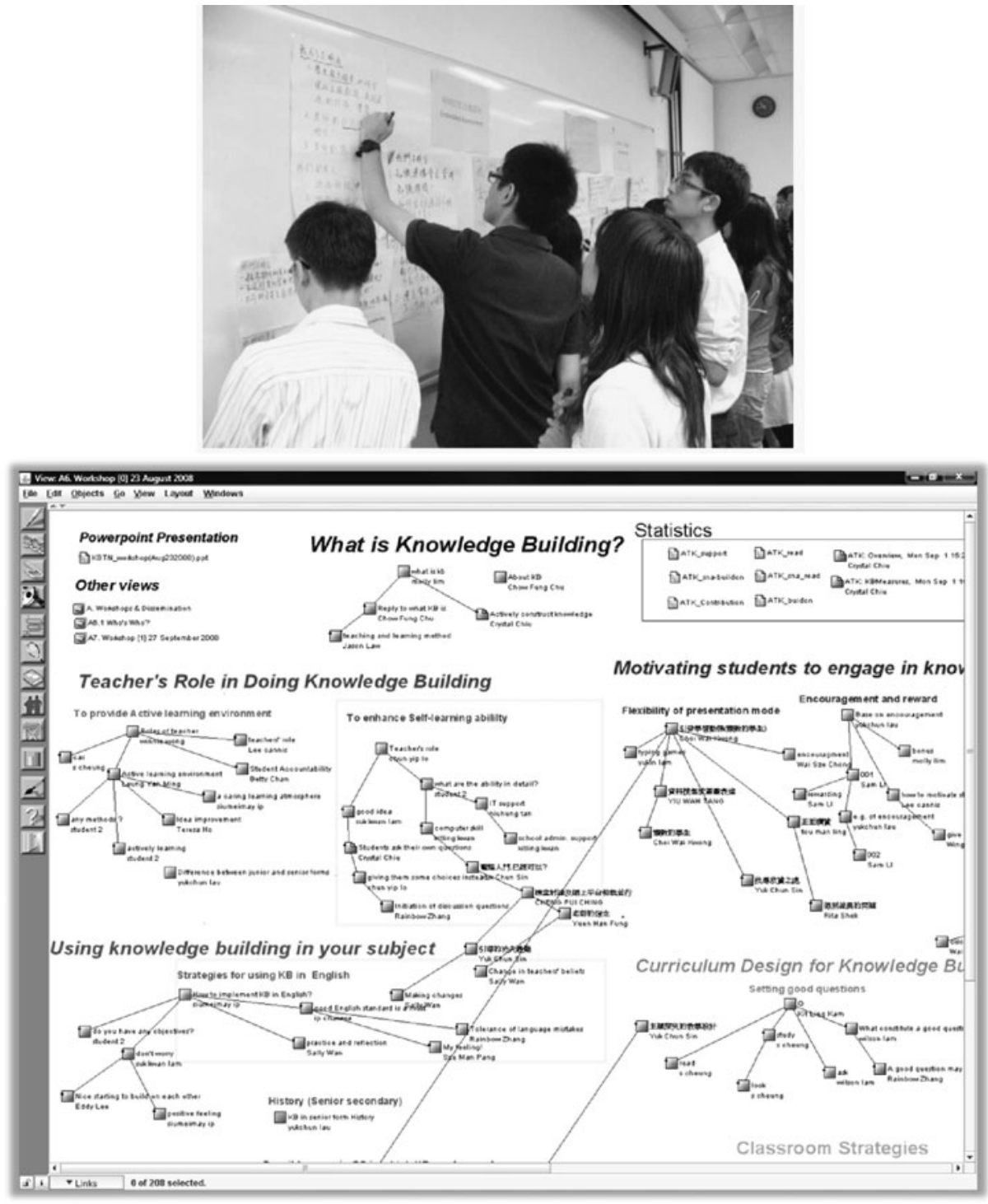

Fig. 1 Teachers working with ideas and engaging in collective inquiry on Knowledge Forum

Teacher F: Um... I think it is difficult for students to find out their ideas [themselves] .... Maybe the teacher can write down important points that have been raised on the blackboard to make their idea clearer. (\#3)

Teacher B: It may depend on the ability of the students. If the students in some classes are very bright, maybe they can reflect on what they have discussed? (\#4)

Teacher E: I wonder if it is a good idea that the teacher points out the important ideas. It may be better if the students themselves can find out what is important... and then ask more questions in their [subsequent] problem solving process? (\#5) 
Teacher H: Maybe the teachers can work with students together to find out the important questions and ideas they have raised (\#6)

Teacher B: We talked about ...idea change and improvement... If students can identify these changes, it would be important. ... [didn't think about that before] but need to focus more on students reflecting on what they know (\#7).

Although the teachers' understanding of knowledge-building principles is rudimentary, they were not just discussing practical methods but examining the classroom episode in terms of big ideas and problems (e.g., "what about assessment?" \#1). This question is somewhat similar to "I need to understand," a problem-formulation discourse move to start inquiry. Teachers put forth initial "theories" (\#2, \#3, and \#4) as they elaborated on others' ideas and grappled with the tension of structured versus emergent design, a key notion of knowledge building. The idea of giving students more agency (\#5) was responded to with an effort to synthesize the different ideas (\#6). This is followed by another teacher's reflection on how their inquiry is related to the principles of agency and idea improvement (\#7). Such collaborative discourse was quite emergent and seemed important to help teachers move gradually to a deeper understanding of knowledge building. In subsequent interviews, one teacher said:

"Although we may be doing the same activities such as students asking questions... I see the differences now about why asking questions is valuable-It is about facilitating the whole community to make advancement. There is also something key about ownership and agency as students are the ones who pose the questions, and amazingly they are the ones who can even assess their own understanding."

(Interview with a teacher, TYB)

The excerpt suggests that the teacher might now be examining her classroom work, considering not just "how" but also "why" the classroom processes in connection with the principles. From a focus on activity, teachers moved gradually towards the emphasis on principles. Figure 2 shows an example of how one teacher spontaneously created an artifact to show her interpretation (model) of principles that sparked a collective inquiry among other seconded teachers at the design meeting.

\section{Teacher-researcher collaboration and community building}

Over time, less emphasis was placed on formal divisions of labor, and more emphasis on socio-cognitive dimensions and community building. With the wide range of expertise, the design is to have teachers support and scaffold each other as they work on shared problems. During the workshops and meetings, teachers were provided opportunities to share their experiences with their peers; they also worked on building knowledge together using a teacher database. For multiple zones of proximal development, year 2 teachers might share with newcomers the problems they encountered and strategies employed when they first started with knowledge building while they tried to further what they needed to know by working with the more advanced teachers. Seconded teachers act as peer coaches who work at the edge of their competence, providing models for new teachers while they work with their peers and researchers to improve their designs. Changes seemed to be emergent and voluntary, with some teachers spontaneously grouping together to open their classrooms for visits from network teachers, identifying intriguing examples of student discourse for inquiry, 

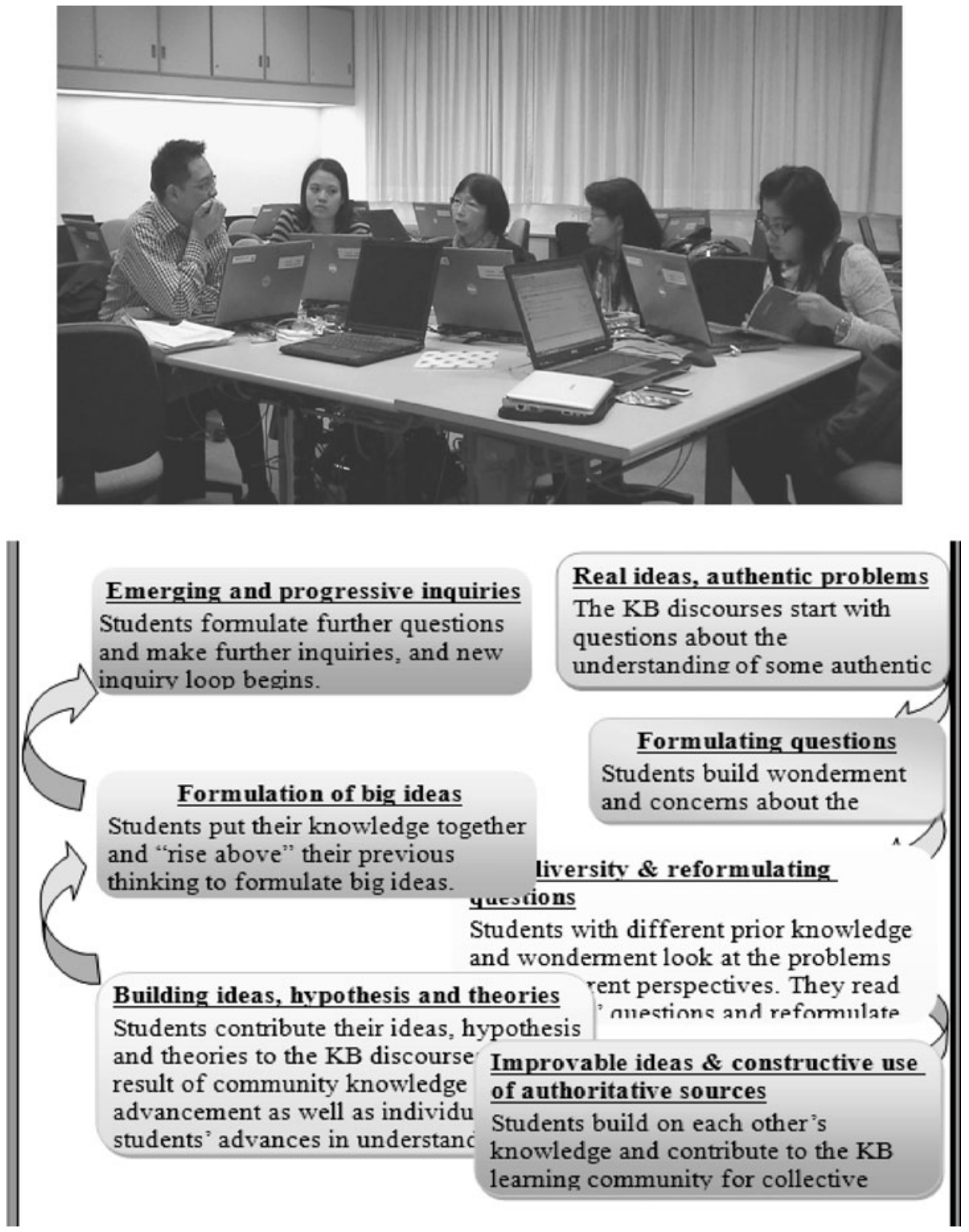

Fig. 2 Teachers creating an artifact for inquiry into knowledge building principles and practice

or videotaping their own lessons as shared artifacts. At the same time, there were also unexpected surprises, as when some strong teachers stopped participating.

Another theme was to work towards creating new knowledge using a design-based approach. While these teachers were from different curriculum areas, many were interested in designing assessments to foster knowledge building. For example, one seconded teacher spontaneously examined what she did in year 1, tried a new design in 
year 2, and brought back ongoing student forum work for group discourse. The collaborative inquiry led to another round of designs that employed more technological affordances (i.e., reference notes) while tapping into the idea of collective cognition. Her design efforts were scaffolded and advanced by others' questions. Meanwhile, another teacher in the group developed a related design, but one more relevant to his classroom context with low-achieving students. During the process, teachers and researchers were co-inquirers and co-designers - these teachers scaffold their students to reflect; they created assessment artifacts while they were advancing their knowledge about concurrent assessments of knowledge building.

\section{Technology-enhanced inquiry}

The technology used in KBTN includes Knowledge Forum and its related suite of assessment tools (Table 2). Although KBTN teachers could use the basic functions of Knowledge Forum, they did not understand how the technology affordances are connected to the principles for fostering collaboration. One strategy is to have teachers work on a teacher database during meetings, as teachers usually do not have time to write on the forum. Phase 2 set aside time during teacher workshops to encourage teachers to write on the database. Teachers were asked to work on Knowledge Forum to inquire into some authentic problems or to use rise-above notes to track progress. One new teacher commented, "I thought writing notes was easy and here when I am trying to build on what others have written, and to articulate my views and synthesize some ideas, I began to see more what my students have to be working on."

In order for teachers to use the technology, it must be ecologically compatible with classroom and school norms. Teachers need to find out whether their students benefit from the innovations; assessment of student work on Knowledge Forum thus becomes important. Teacher development design includes working with teachers to use the assessment tools in ways that connect with both principles and classroom needs. The software Analytic Toolkit (ATK) and Applets, which accompany Knowledge Forum, can provide overviews of student work, using server logs to identify usage statistics. ATK basic indices-write, read, revision, scaffolds, links, and keywords - can be used by teachers for formative assessment with students. Another set of assessment tools used by KBTN teachers are the Applets for Social Network Analyses - these analyses provide information on note-reading and buildon density to show if students are interacting with each other. The ATK and Applets are tools for researchers and teachers, and they can also be used by teachers and students to assess their own progress. KBTN teacher-development activities include helping teachers use these tools in ways to further their understanding of knowledge building. For example, teachers use these tools to find out whether their students were developing more connectedness as a class community (Fig. 3). Although there are different levels of uptake, some seconded teachers have developed repertoires in using these assessment tools and integrated them into their classroom work.

Phase two (2006-2008): Analysis and ongoing evaluation

The network began with seven teachers as seconded teachers; since its second year, the project has had about 40 to 50 teachers participating. While there is considerable fluctuation, more than 25 teachers have continued with the practice for more than 3 years. Although the number is modest, this continuity suggests that the use of CSCL pedagogy has become more regular and integrated into the practice of some teachers. 
Fig. 3 Using the Applet tools for formative assessment of student participation on Knowledge Forum



Changes in the quality of student discourse

Teachers joining the project were facilitated to implement knowledge-building curricula supported with Knowledge Forum. Students from Grades 4 to 12 worked on different curriculum areas and inquiry topics in science, humanities, and language, including environment, energy, human body, sustainable development, poverty, community, identity, political participation, and reading novels. These topics have been adapted into the curriculum in relation to the requirements of schools and the Education Bureau.

There were 40-50 teachers each year, and most worked with one class, although some led more than one class or collaborated with other teachers. We selected the classroom work that lasted for at least 3-4 weeks for analyses of participation and quality. In the first 2 years, there were many databases with scattered and fragmented notes; some databases included only one or two notes per student. By year 4, more classrooms were participating actively, with students contributing from four to 20 notes each.

The quality of student discourse on the forum was examined using a scheme developed jointly by the researcher and the teachers, arising from the need to provide some overview of the quality of student discourse to guide further classroom work. The coding scheme, adapted from types of knowledge-building discourse (van Aalst 2009), consists of four levels: (a) fragmented and assignment-oriented, (b) knowledge-sharing, (c) knowledgeconstruction, and (d) emerging knowledge-creation discourse. The new scheme was tested with some databases (Chan and $\mathrm{Fu} 2011$ ) and extended to the range of classroom databases. At the lowest level, students wrote fragmented or unconnected responses to teacher questions with short exchanges; the next level called knowledge sharing refers to superficial interactions with conversational exchanges, and the sharing of opinions and information. Towards a more productive discourse, knowledge construction involves the co-construction of ideas identified with statement of problem, questions and explanation, and the constructive use of information. There were some discourse threads that reflect emerging knowledge creation with meta-discourse, emergent questions, and awareness of community dynamics with reference notes as well as rise-above notes.

The various classroom databases were examined for the quality of student discourse on Knowledge Forum. Typically, each of these classes consisted of several views (discussion areas), and only the view with the best discourse was coded to represent what students could do. Table 3 shows the patterns of discourse over the years 2006-2010. By the end of year 4, fewer classes showed students writing fragmented responses or providing answers to teacher questions as was observed in the preceding years. There was also a reduction in knowledge- 
Table 3 Changes of the quality of student discourse on Knowledge Forum for KBTN classes, 2006-2010

\begin{tabular}{lcllll}
\hline Year & \multicolumn{2}{l}{ Quality rating of student discourse } & & $\begin{array}{l}\text { Number } \\
\text { of classes }\end{array}$ \\
\cline { 2 - 5 } & Fragmented & $\begin{array}{l}\text { Knowledge } \\
\text { sharing }\end{array}$ & $\begin{array}{l}\text { Knowledge } \\
\text { construction }\end{array}$ & $\begin{array}{l}\text { Emerging knowledge } \\
\text { creation }\end{array}$ & $3(7.5 \%)$ \\
\hline $2006-2007$ & $12(30 \%)$ & $18(45 \%)$ & $7(17.5 \%)$ & $10(14.4 \%)$ & 60 \\
$2007-2008$ & $28(41.0 \%)$ & $23(33.7 \%)$ & $7(10.8 \%)$ & $6(9.5 \%)$ & 63 \\
$2008-2009$ & $8(12.7 \%)$ & $37(58.7 \%)$ & $12(19.1 \%)$ & $8(15.1 \%)$ & 53 \\
$2009-2010$ & $10(18.9 \%)$ & $20(37.7 \%)$ & $15(28.3 \%)$ & & 68 \\
\hline
\end{tabular}

sharing discourse and an increase in knowledge-construction discourse patterns. Although this rating scheme only provides an overview, the analysis helps to identify key patterns that distinguish information-sharing from knowledge-construction discourse and that can be used by teachers. At the same time, it provides a basis for further research currently being undertaken to unravel the discourse patterns, to examine how discourse is created in the social context, and to explore how teachers may use it to scaffold student discourse.

\section{Changes of student participation}

As the seconded teachers are the key players in the network, it would be useful to examine how or if they have changed over the years. Following the analyses employed in the study of knowledge-building teachers, the participation patterns of their students were examined to identify any changes. Three quantitative indices, derived from the Applet tools, were included: (a) the students' contribution to the community, based on the number of notes written; (b) their awareness of the contribution of others, based on the density of notereading; and (c) their connectedness with others' notes, based on the density of linked and build-on notes (Zhang et al. 2011). The density of a network is determined by the number of lines between nodes divided by the maximum number of all possible lines, the value being between 0 and 1 . The increased note-reading and build-on density suggests that the classroom communities of these seconded teachers were becoming more connected (Table 4); these indices are comparable to those of knowledge-building teachers in Canada (Zhang et al. 2011).

Table 4 Changes of student contribution towards more connectedness based on the Knowledge Forum Applet indices for seconded teachers

\begin{tabular}{|c|c|c|c|c|c|c|}
\hline \multirow[t]{2}{*}{ Teacher } & \multicolumn{2}{|c|}{ Number of notes written } & \multicolumn{2}{|c|}{ Note-reading density (\%) } & \multicolumn{2}{|c|}{ Build-on density (\%) } \\
\hline & 2008-2009 & 2009-2010 & $2008-2009$ & 2009-2010 & 2008-2009 & 2009-2010 \\
\hline TLC & 5.5 & 19.2 & 41.66 & 85.71 & 13.76 & 32.63 \\
\hline TTH & 19.9 & 25.2 & 94.2 & 95.4 & 27.36 & 33.23 \\
\hline TPY & 12.2 & 12.5 & 95.15 & 100 & 33.28 & 37.98 \\
\hline TSW & 10.1 & 4.2 & 82.07 & 97.89 & 17.63 & 26.84 \\
\hline TSY & 6.7 & 17.7 & 66.31 & 90.64 & 16.29 & 31.41 \\
\hline TWS & 5.0 & 14.8 & 80.55 & 88.06 & 19.66 & 43.37 \\
\hline
\end{tabular}




\section{Shifts in understanding}

KBTN provides a rich test-bed for different analyses to understand knowledge-building innovation. Currently, analyses are being conducted on teacher beliefs and practice, and there are several possible areas that may contribute to the teachers' growth; these areas reflect teachers' shifts in understanding and suggest areas for further inquiry.

(a) Pedagogical model. A knowledge-building inquiry pedagogy model was developed and adopted, incorporating the principles and featuring four phases appropriate to the socio-cultural context: (a) creating knowledge-building norms and cultures-acculturating students to collaborative dynamics in classrooms; (b) problem-centered collective inquiry - extending classroom discourse and inquiry within the forum; (c) synthesis and rise-above-working towards community knowledge by synthesizing notes and creating new views for rise-above; and (d) embedded and concurrent assessment - conducting assessments to foster knowledge building. This pedagogical model was first employed by one or two teachers, was refined, and is now widely practiced within the network. While Scardamalia and Bereiter (2006) argue against activity structure, these cyclical phases are principle-based that align with the sociocultural contexts. Empirically, they were derived from failed cases and iterations in which teachers introduced Knowledge Forum without first working with classroom norms, and the other phases were gradually developed over the years based on teachers' classroom experiences.

(b) Principles of assessment and assessment artifacts. The idea of designing e-portfolio assessment to examine and foster assessment has been developed in research studies (Lee et al. 2006; van Aalst and Chan 2007). Within the KBTN, this model was examined, tested, and refined in multiple sites, with adaptation and appropriation being used to determine how it might best suit different curricula and school levels. The e-portfolio was relatively complex and iterative design efforts were developed with designs that were more applicable to the classrooms. For example, several teachers now work with students to come up with what they consider to be good examples of discourse and from there to derive the principles by which they could assess their own discourse.

(c) Knowledge-building in non-science domains. The knowledge-building model has been used almost exclusively in elementary science in the international literature. Traditionally, social sciences and language teachers usually focus on argumentation. The KBTN language teachers have moved beyond the usual genre of argumentation to examine how knowledge building that focuses on theory revision might work in nonscience areas. Some examples include having students work on concepts such as "filial piety" or "poverty," viewing them as objects of inquiry, and moving from naïve, common sense ideas to more sophisticated notions. It is not yet clear what these lines of inquiry might yield; however, they involve more than sharing good practice and may include building new knowledge and make possible research into the intertwining areas of argumentation and knowledge building.

While there were some advances and, in particular, growth of some teachers, there were also many challenges. Primarily, knowledge building itself is a complex model and scaling up in ways that preserve its nature yet remain applicable to a large number of teachers is challenging. Relying on expert teachers as key resources for spreading innovation is the dominant strategy, but how peer coaching works is relatively unexplored. However, through 
failed and successful attempts, uneven patterns and wide variations, surprises, growth, and attrition, there has been emergent growth in the teacher network with many teachers sustaining the practice over the years and developing new innovations.

\section{The micro context: Knowledge-building practice in the classroom}

This section reports on classroom design and illustrates how research can be integrated into the classroom level by focusing on principles, technology, and socio-cultural dynamics. For macro-level reforms to succeed, classroom design and processes and how they can be supported by meso-level changes must be examined. Barab and Luehmann (2003) note the need to examine how teachers accommodate changes to research models for sustained innovative practice in the science curriculum. There are various other cases of knowledgebuilding teachers (e.g., Chan 2008; van Aalst and Troung 2010); this particular case has been selected because the teacher has sustained the practice and has remained close to the model while appropriating it to suit the local context. Although Mr. K's practice is not the most typical among other teachers, it shows possibility and vision and it serves as an impetus for others to make changes as they spread the innovation.

\section{Background}

Mr. $\mathrm{K}$ is a chemistry teacher who has sustained knowledge-building pedagogy in his classroom for over 8 years (2002-2010). He is a key KBTN member, both as a classroom teacher and as a teacher associate providing support to new network teachers. While knowledge building is conducted mostly in elementary science classrooms, Mr. K introduced knowledge building to his senior-form (Grade 12) chemistry students in 2002 following the work of another teacher. After the initial round, Mr. K implemented knowledge building with a cohort of Grade 10 students. Interestingly and fortuitously, this coincided with the global SARS crisis and a 5-week school suspension in Hong Kong. Whereas many teachers in Hong Kong used the Internet merely for information delivery during this period, Mr. K's students worked on Knowledge Forum, inquiring into chemistry problems of which some were related to the SARS problem (e.g., chlorine bleach as a disinfectant). This was an important early experience for Mr. $\mathrm{K}$ - with limited teacher instruction, the students took on major collective cognitive responsibilities in pursuit of understanding. In the following years, Mr. $\mathrm{K}$ continued his practice, which varied in complexity depending on organizational constraints such as workload. His practice was enriched by his KBTN participation, and he, in turn, contributed to the teacher network. The following section uses his most recent two iterations of Grade 10 classroom design.

Classroom design integrating principles with the socio-cultural context

As discussed before, the knowledge-building inquiry pedagogy model was a special feature developed in KBTN and was implemented in this chemistry classroom (Fig. 4). Table 5 shows further how the principle-based curriculum design was appropriated to the socio-cultural context of Hong Kong classrooms. Primarily, the teacher started with creating a collaborative knowledge-building culture helping students to make their ideas public followed by research and collective inquiry on Knowledge Forum. Students continued to improve and advance community knowledge through creating higher-level ideas and meta-discourse using Knowledge Forum affordances, as well as advancing their 


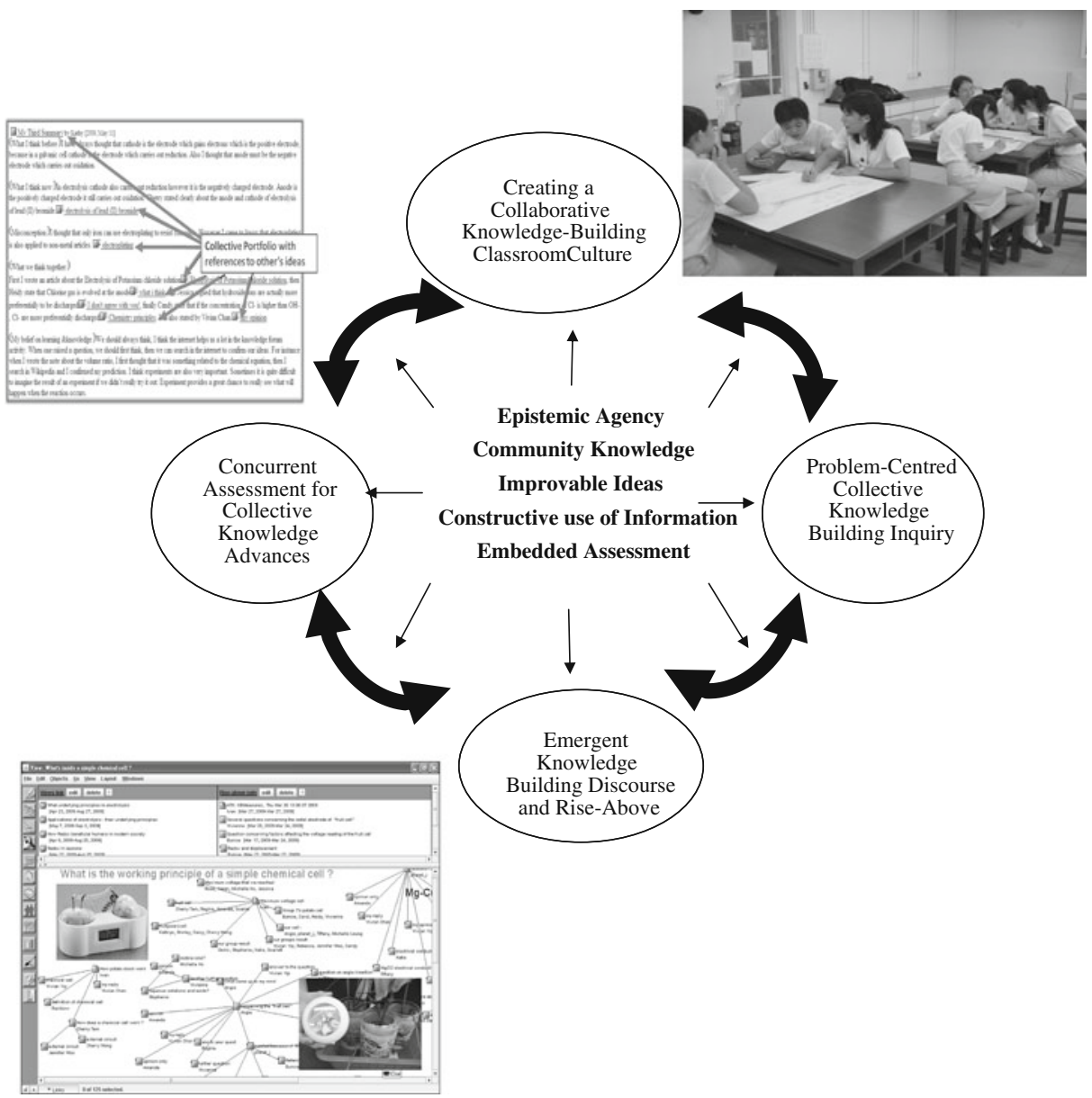

Fig. 4 Knowledge-building inquiry pedagogy model developed in KBTN and implemented in a chemistry classroom

collective knowledge through concurrent and embedded assessment with new emerging questions. It is useful to note that emphasis was given to emergent and cyclical inquiry rather than linear steps to follow (Fig. 4). Scardamalia has proposed a set of 12 principles; the KBTN teachers in Hong Kong have focused on five of these principles most applicable in the classrooms. The following is an interpretive account to illustrate how the teacher employed a principle-based design while appropriating the model to the socialcultural context.

\section{Epistemic agency}

In Hong Kong classrooms, where students are used to teacher-centric knowledge transmission, KBTN teachers, including Mr. K, usually start by changing classroom norms through classroom discourse, in what some would call Phase One of the model. The teacher encouraged students to start to engage in discourse in dyads, groups, and class 
Table 5 Principle-based curriculum design appropriated with the socio-cultural context of Hong Kong classrooms

Knowledge-building inquiry Themes Principle-based pedagogy

Creating a collaborative knowledge-building classroom culture

Problem-centered collective knowledge-building inquiry

Emergent knowledge-building discourse and rise-above

Concurrent assessment for collective advances
Hong Kong students used to transmission mode acculturated into the practice of putting forth their ideas to the public for inquiry and improvement

Students articulated ideas for inquiry; raised questions; commented on others' views; elaborated explanations; core curriculum ideas as well as routine school materials turned into objects of inquiry

For spatial-technological constraints, Hong Kong students worked on Knowledge Forum at home

Teacher provided models initially (e.g., I wonder)students posed authentic problems, made conjectures, co-constructed explanations

Knowledge Forum affordances (e.g., scaffolds) prompted epistemic agency for theory revision. Students made constructive use of information and worked on improving their collective ideas for theory building

Competition common in Hong Kong classrooms is melded with collaboration

Model-based explanatory inquiry — students initially worked in own groups to construct the "best" chemical cell; they then explained and compared different models putting their knowledge together supported with forum affordances

Students worked collectively on "rise above," "references," and meta-discourse for coherent explanations and building community knowledge

Integrate collective assessment with domain understanding needed for public examination

Students viewed notes on forum, assessed and reflected on their initial beliefs and conceptions, and tracked their changing ideas supported with conceptual-change scaffolds on Knowledge Forum

Students grappled with alternative models sparking idea improvement, wrote e-portfolio with meta-discourse for advancing collective knowledge, and raised new emergent questions for continued collective inquiry 
communities. This is quite different from knowledge-building classrooms in Canada, where students start their inquiries directly on Knowledge Forum. The same pattern is adopted in both Hong Kong and Singapore classrooms, reflecting the role of socio-contextual influences in classroom innovation.

Reform-oriented teachers are familiar with the idea that students need to have ownership. This principle further emphasizes the epistemic dynamics of individual and collective cognition (Scardamalia 2002). Often, teachers set problems for their students to answer, solve, or explain, as Asian students expect good teachers to do. Mr. K's strategy involves modeling through examples, gradually relinquishing cognitive responsibility to the students. Although the researcher had suggested that students put forth their own ideas and questions, the teacher initially posted problems on Knowledge Forum but tweaked them in ways that encouraged students to gradually begin posing problems of their own. It is not clear whether this was intended or emergent; however, it is perhaps another example of a teacher appropriating the knowledge-building model in relation to social-cognitive processes and socio-cultural context.

While the initial questions were either shallow or textbook-based, the teacher worked with students to help them to pose authentic problems that needed to be explained using chemistry principles (e.g., silver tarnish and redox). They examined differences between their ideas and those of others and worked to resolve them to spark knowledge advancement. In Phase Two, when they collaborated further on Knowledge Forum, cognitive-technological dynamics supported their epistemic agency-KF scaffolds (e.g., I need to understand, my theory, new information, putting our knowledge together) are not merely sentence openers; they are epistemic scaffolds to help students pose problems, put forth preliminary theories, construct and refine them, and synthesize and put their knowledge together. Epistemic agency continues to be a challenge given the important role of teachers in Asian classrooms-Hong Kong students might be actively engaged in knowledge construction but they need to shift further towards engaging in knowledgecreation efforts as part of a scientific community.

\section{Community knowledge}

The major shift needed to establish a knowledge-building classroom is to help students understand that, rather than working as individuals, they can act as a community to make advancements collectively. Mr. K and other KBTN teachers had the challenge of getting their students, who are used to a competitive Asian school system, to accept one that prizes individual and collective growth equally. At the beginning, some students might have felt that sharing their best ideas with others on Knowledge Forum would hurt them in examinations, and teacher discourse at the KBTN addressed this. From the start, Mr. K used group concept-maps, posters, and knowledge-building walls to make ideas public, a strategy developed simultaneously in knowledge-building classrooms in other countries. As students continued their inquiries on Knowledge Forum, they gradually seemed to realize that individual and collective knowledge growth interact and go together. Phase Three includes a synthesis of different ideas in "rise-above" notes and reflective summaries that further capture and scaffold students' community knowledge. Competition is common in Asian classrooms. It seems paradoxical, but Mr. $\mathrm{K}$ cleverly melded competition with collaboration-student groups first competed on constructing the best chemical cells, and then these different models were put on Knowledge Forum as objects of inquiry, for the class' collective knowledge advances about chemical cells. 
For ongoing analysis of and feedback on his classroom design, the teacher, as did other KBTN seconded teachers, employed ATK and Applets to track the participation and connectedness of the class community. The integration of CSCL technological and assessment tools into classroom practice helped him to gauge whether his class was improving as a closely knit social network, and he discussed such assessment information with his students as he reflected on the design.

\section{Idea improvement}

This principle emphasizes viewing ideas as objects of inquiry - the quality and coherence of all ideas can be improved upon through collective work. Mr. K encouraged students to put up their ideas for inquiry so the community could work on improving the ideas and explanations. Different practices in Mr. K's classroom, ranging from building onto others' ideas for theory refinement, rise-above notes, and reflective summaries, all reflect the focus that ideas can be improved. Idea improvement has metacognitive and epistemic aspectsstudents examine ideas and consider what needs to be improved and how (e.g., how can these ideas be better? What else do we need to know?)

In some ways, idea improvement is an interesting principle for Asian teachers and students with the typical Chinese learners' appreciation of the importance of effort (Watkins and Biggs 1996). The KBTN teachers, including Mr. K, tweaked in ways to include both cognitive and social aspects; Mr. K emphasized that all ideas are improvable (object for inquiry) and that students could improve and should help each other to improve their ideas. Although improvable ideas is an epistemic concept different from the notion that students should improve themselves, the perplexing congruence of cognitive and socio-affective dimensions may work together. A delicate balance exists in how teachers interpret improvable ideas so they do not just assimilate that to the common notion of improvement but to keep working at the pursuit for epistemic quality.

\section{Constructive use of authoritative information}

Knowledge building for creation of ideas involves knowing the present state of knowledge as well as working at the cutting edge. This principle emphasizes students' use of authoritative resources along with other information as resources for idea improvement and theory revision. Knowledge Forum also includes scaffolds such as "new information" on which students can base their elaboration and revision of their theories. With the emphasis on learning how to learn and project-based learning, teachers in Hong Kong are quite familiar with the notion of information search but they need to advance such understanding for more emphasis on using information for theory building.

Mr. $\mathrm{K}$ encouraged his students to make constructive use of information, providing evidence as they explained their theories. Generally, the class started with students posing questions and problems and, as they worked to solve the problems, they would seek information from Internet chemistry databases, including Wikipedia, in support of their knowledge-inquiry processes. At the beginning, students tended to copy information from the Web directly as answers to their peers' questions, and after a short exchange, discourse stopped and inquiry was considered as completed. The teacher and the KBTN group worked on these debilitating strategies and student beliefs. Classroom discourse was conducted on students' different ways of using authoritative information and how they could use such information to elaborate and revise their theories for further inquiry. It is another challenge as Asian students usually view textbooks and teachers as authoritative 
sources. Analyses of e-portfolio on Knowledge Forum indicate that some students began to question the textbook information as they pursued new understanding ("I have not considered those other factors...our textbook often shows electrode smoothly covered with the metal, but it is not so in real-life").

\section{Concurrent and embedded assessment}

This principle emphasizes assessment as a way to advance community knowledge. Often, assessment is an external measurement; here it is used to foster and scaffold collective inquiry. While the other four principles have all been widely discussed elsewhere in the knowledge-building literature, this principle has attracted much attention from Hong Kong teachers and has been advanced through the collective efforts of KBTN teachers.

Mr. K and other KBTN seconded teachers attached much importance to assessment throughout the process. Typically, ATK was used to track student progress for formative evaluation. KBTN seconded teachers also developed the practice-explicit criteria of participation were developed with students so they could understand what was expected of them in terms of reading, building-on, and contributing to others for community advancement.

Mr. K first adopted the e-portfolio from another network teacher and then adapted it into different forms as he interacted with other KBTN teachers. In the current design, his goal was to use assessment to examine and foster conceptual change. In the first iteration, the assessment scaffolds (e.g., what are some important ideas about X that you have learned?) focused much on the content of what students had learned, and the e-portfolio did not show the process clearly. These not-so-successful attempts then led to revision of the assessment design refined to include the conceptual-change scaffolds (e.g., what I thought earlier, what we discussed, what we now thought, what I have learned). This revision helped the students to reflect on their initial conceptions as they considered individual and collective advances. While this portfolio design was co-constructed with the researcher-teacher community based on the notion of collective cognition, it also aligned well with the needs of Hong Kong teachers and students for deep domain knowledge for examination purposes. Although the assessment approach has been useful, there is also the challenge of how KBTN teachers can tackle the tension between developing cultures of emergent assessment versus designing guided assessment tasks. This is an issue of continuing challenge among teachers in KBTN.

Analysis and ongoing evaluation

Classroom innovation in knowledge building involves teachers reflecting continually on the processes of their knowledge-building classroom designs. The process of inquiry also includes examining student progress and outcomes, as teacher development needs to be examined in relation to student growth. Formal analyses have been conducted with data sources including Knowledge Forum participation, Knowledge Forum discourse, conceptual-change tests, examination scores, and student and teacher interviews (for details, see Chan and Lam 2010). A summary is provided here: Data analyses show that students participated actively on Knowledge Forum (number of notes, 21.5; note-reading density, 99\%; build-on density, 28\%). Significant differences were shown on conceptualchange scores from pre- to post-tests with a comparison class. Results also showed that the extent to which students were engaged in Knowledge Forum (ATK indices) was correlated with the quality of the collective inquiry (based on e-portfolio), which in turn predicts the conceptual-change scores. Discourse analyses suggest that articulation of "misconceptions," question-explanation sequence, and constructive use of information were important 
discourse patterns. Interestingly, the teacher took the initiative to analyze examination results and found that student participation and engagement on Knowledge Forum were correlated with their public exam results in chemistry.

Many teachers were hesitant to adopt innovative approaches for fear that they might harm exam results that measured different competencies. However, throughout his involvement, Mr. K has found that when his students wrote more and collaborated more with others, they obtained better examination results. This is an intriguing phenomenon that might be related to the teacher's belief that deep collaborative inquiry does not necessarily contradict with what is required in examination, a major challenge for CSCL/learning sciences research to be implemented in classrooms. This is not a widespread belief, and other KBTN teachers have dropped out of the project due to exam pressures. These perplexing variations highlight the need to understand teacher beliefs in relation to the socio-cultural-historical milieu of the classroom systems.

From the perspective of coordinated changes across levels, Mr. K's classroom innovation was supported at the school level as it coincided well with the government's call for pedagogical and technological innovation. His practice was nourished by the teacher network at the meso level, and he, in turn, enriched the network through sharing experiences and building his knowledge with others. His innovation can be sustained because it is principle-based and appropriated for the contextual dynamics of the Hong Kong classroom. Over the years, the teacher's sustained practice is supported with designbased research leading to continual improvements in the innovation. Such practice fits well with the notion of social infrastructure considering beliefs, practice, technical-spatial characteristics, and connections with the outside community (Bielaczyc 2006).

Mr. $\mathrm{K}$ has a strong academic background and he is now engaged in thesis research. The diffusion of his sophisticated model to other teachers will certainly take much time. As with most Chinese teachers that value classroom organization and structure, the teacher constantly grappled with tensions of carefully guided design versus emergent understanding and culture. Knowledge building requires teachers to surpass themselves but, given the strictures and pace of Hong Kong curricula, whether these expert teachers can appropriate the necessary space to grow and not just plateau at a certain performance level also bears consideration.

\section{Key themes and lessons learned for integrating CSCL research and practice}

This paper has addressed the limited impact that research has on classroom practice and has examined issues related to how CSCL research can be integrated into classroom systems for educational impacts. A case study of implementing and scaling-up knowledge building in Hong Kong classrooms has been illustrated at the macro, meso, and micro levels (institutional support, teacher network, and classroom practices, respectively). Figure 5 is a schematic representation of context, processes, and dynamics at different levels for classroom innovation. Three main themes have emerged - context and systemic changes, capacity and community building, and innovation as continual inquiry. These themes will now be discussed to address questions of designing collaboration for educational innovation and to explore conditions facilitating knowledge creation and sustained innovation for educational impact.

Context and systemic changes

The first theme is that designing collaboration for classroom innovation is complex; changes are emergent and facilitating conditions would include examining and aligning 


\section{Macro-Level Context}



Fig. 5 Contexts and dynamics for sustainable knowledge building in Hong Kong classrooms

goals and processes that occur at multiple levels. While the macro level provides the initiative, actual change takes place at the evolving meso and micro levels with feedback to different levels. The following discussion examines different levels, but emphasis will be given to coordination and alignments for facilitating classroom practice.

\section{Education policy, curriculum reform, and cultural beliefs (macro-level processes)}

At the outset, policy context sets the stage for innovation and change by institutionalizing as well as encouraging school-based pedagogical and technological development (Dede and Honan 2005; Goldman 2005). Against the macro contexts of major policy changes for education and ICT reforms, the Knowledge-Building Teacher Network was developed to implement the educational model of knowledge building and to advance both research and practice. KBTN is designed to help teachers, principals, parents, and policy makers view the research model as consistent with the goals advocated in education reform initiatives, 
such as communication, collaboration, inquiry, and technology-enhanced learning. For educational impact, CSCL research must be aligned with the goals of education reforms.

Researchers have suggested that ministries of education are often unwilling to fund research into questions in which they have no interest (Schoenfeld 2006). As such, one consideration of policy-research-practice synergy is to examine how to identify and reframe questions so that they align with ministry goals while still advancing the research agenda. CSCL research can drive educational reforms, and examining the nature of collaborative learning and how CSCL pedagogy and tools can work in the classroom are important to research and practice. Just as macro and institutional contexts influence research and classroom implementation, innovative models and new insights derived from the classrooms may also influence government policy decisions.

Macro-level processes include institutional changes as well as historical-culturalepistemological values and norms influencing changes at other levels. While ministrydefined education reform goals for the twenty-first century emphasize skills, school communities often see these pronouncements as clichés that may weaken the existing curriculum, and collaborative learning is viewed as merely conversation rather than as a knowledge-building process. Lessons learned from this study suggest that insights from CSCL and learning sciences research — which emphasize deep knowledge for inquiry-based learning - could help to allay teachers' concerns, with KBTN bringing these findings into the schools. As discussed before, the revamping of curricula in accord with new reform goals often must proceed alongside a continued emphasis on examinations, even though these ideas seem incompatible. This is not the case in Asian schools alone-researchers in the West have also had to address the problem of developing collaborative inquiry while dealing with institutional constraints and increased emphasis on standards and testing. The various tensions and constraints related to macro-level societal, political, and cultural concerns and alignments are challenges that need to be considered everywhere.

\section{Enabling structure and partnership (meso-level processes)}

Collaboration and partnership are key components of systemic change-improvement efforts should involve participation and support from people at multiple levels. While macro-level policy and institutional changes may set the stage, wide gaps exist between educational policies, research findings, and the classroom.

University-school partnerships adopted for large-scale educational innovation (e.g., Fishman et al. 2004; Laferrière et al. 2007), and here with KBTN, can facilitate useful meso-level processes for aligning changes and creating partnership and collaboration. While ministries, schools, and universities can be seen as distinct groups with different cultures and diverse interests, they may intersect with each other as they advance towards their respective goals. The government's reform goals may be carried out in schools with the support of expertise from university members; researchers may receive government funding and endorsement to introduce new ideas with access to school sites; teachers may meet ministry reform benchmarks with professional development support from universities.

Meso-level processes involve mapping, translating, interpreting, and linking the discourse of different parties and communities. The KBTN efforts include adaptation of macro-level emphasis and contextualizing research discourse at the pedagogical sites, such as interpreting educational reform goals in line with a knowledge-building model, working with teachers to align school demands and requirements, setting up technology that fits classroom and teacher needs, designing pedagogy that meets the assessment and examination demands prevalent in Asian schools, and helping teachers to understand 
changes in student collaboration and discourse. Different parties may work together in building new knowledge despite having different goals. Scardamalia describes a knowledge-building principle she calls symmetrical advances (2002), which may be employed to describe such phenomena of collaboration across different sectors.

\section{Alignment of cognition, design, and context (micro-level classroom processes)}

Integrating CSCL in classroom practice requires careful orchestration including coordination of curriculum, pedagogy, and technology affordances (Dillenbourg et al. 2009) and consideration of the social infra-structure of classroom innovation (Bielaczyc 2006). Zhang (2010) argues for the importance of bridging macro- and micro-level beliefs and practices. Looi et al. (2011) note that it is not enough just for researchers to conduct their question of interest, but they need to consider how different parts can be coordinated to fit the classroom ecology. Studying CSCL research-based innovation in Asia is particularly interesting due to the tensions and dilemmas involved. While Chinese and Asian students have been described as collectivist, they are still, paradoxically, highly competitive and place much emphasis on individual achievements.

One of the lessons learned about sustained practice is that there needs to be acknowledgment and accommodation of the model in light of macro- and meso-level emphases. This paper has described one teacher's emphasis on principle-based design but notes that he also addressed socio-cultural and contextual constraints and dynamics; for example, the traditional emphasis on assessment in Hong Kong is capitalized on and adapted by the teacher network into innovative designs of e-portfolios for different subject areas. Designing for collaboration for classroom innovation requires integrating and adapting CSCL pedagogy and technology in ways that align with students' beliefs as well as appropriation to the socio-cultural contexts. Classroom design needs to be informed by principles to retain the spirit of the research, but activities may vary based on macro- and meso-level processes and constraints, contextual dynamics, and socio-cultural milieu. While this paper illustrates these transforming processes using the example of Hong Kong classrooms, this theme is important for research-based innovation in other classroom systems.

Building capacity and community building

A major challenge associated with research impacting on classroom practice is the capacity gap (Fishman et al. 2004) and the need to build up human and social capital (Resnick 2010). How do teachers come to adopt the innovation facilitated by different people coming into contact with each other and using new technologies? This theme examines the socialcognitive, epistemological, and spatial-technological dimensions of capacity building and the alignment of changes across these dimensions and within multiple contextual levels.

\section{Socio-cognitive and community dynamics}

Communities of practice have now become major approaches to teacher professional development. For collaboration and innovation to take place, it is necessary to create opportunities for teachers to reflect on their ideas and interact with their peers, including articulating conflicts and difficulties. Teachers are busy and have little time to work with researchers on classroom innovation. Institutional support, in the form of macro-level policy and meso-level school culture, ethos, and norms, is needed; for example, the KBTN employed a teacher secondment scheme to ensure that teachers would have sufficient 
release time to work on research-based school projects. Infrastructure and resource support are needed for teachers to engage in innovation.

Consideration also needs to be given to the socio-cognitive dynamics of community building. KBTN consists of multiple levels of expertise; teacher leaders, seconded teachers, teacher associates, intermediate teachers and newcomers, and multiple zones of proximal development provide the opportunity to spark knowledge advances. There are different patterns and trajectories of growth as well as tensions and contradictions as some teacher groups developed fast and others dwindled. The conflicts and failed attempts in the early years of the project seemed useful as teachers need to work through contradiction for revision of their models and practices, and such inquiry needs to be supported in a community. Furthermore, communities are important in that these teachers are engaged in new endeavors against a background of strong demands for examination. As they share their practice, they also obtain support from others who are embarking on similar ventures.

A more challenging aspect of research-based innovation and teacher development is that teachers need to move beyond sharing experience to collective knowledge building. KBTN encourages network teachers to understand and own the innovation by engaging in knowledge building, just as they would hope their students do-write on a teacher knowledge-building database and engage in knowledge-building discourse to tackle difficult classroom innovation problems. Teachers need to experience collaborative inquiry and building knowledge to understand and to engage in socio-cognitive dynamics of working as emergent communities, both within the teacher network and within larger networks. Some teachers in KBTN are connected with other networks locally as well as internationally (Laferrière and Law 2010); the challenge and direction is to create these networks as productive mutually supportive communities.

\section{Principle-based understanding and epistemological shifts}

Inquiry-based classroom innovation is difficult for teachers because it is not aligned with macro-level cultural beliefs or school norms and ethos. Teacher professional development often focuses on know-how, such as how to carry out some lesson activities or how to use a piece of software. Scardamalia and Bereiter (2006) note the importance of principle-based innovation; innovation requires epistemological change among teachers. This case study shows that, in the beginning, KBTN teachers merely assimilated new innovation into their existing repertoire-some were posting questions on the forum and asking students to answer as assignments. Principle-based innovation is challenging but important and fruitful-the principles discussed at teacher meetings were implemented in classroom design, with feedback examined through the lens of principles; some teachers began to use principles to help students to become aware of their work on Knowledge Forum. As discussed above, the example at the micro level also shows how the teacher can adapt his activities to the social underpinning of classroom while focusing on the key principles.

Design principles have been commonly used by researchers working on collaborative and inquiry-based learning in classrooms. The idea of principle-based innovation is to focus further on teachers' understanding concerning the nature of the model for innovation. Principles may make the complicated constructs more accessible to teachers for interpretation and integration into classroom life. This study refers to a set of knowledge-building principles but the notion of principle-based understanding would be applicable to other CSCL researchbased classroom innovation as well. For capacity building, moving from activity to principles is important - as teachers understand more, they may begin to own the innovation and become better able to sustain the practice and to adapt it across contexts. 
Knowledge-building work in Toronto has demonstrated the role of the principle-based approach with a group of highly experienced knowledge-building teachers (Zhang et al. 2011). Teacher development in Asian classrooms could provide an opportunity to examine the extent to which a principle-based approach would work for new teachers or those from other cultures. Inquiry into principle-based understanding may address controversies between structured or emergent pedagogy - for example, overscripting (Dillenbourg 2004), guided instruction or inquiry learning (Hmelo-Silver et al. 2007; Kirschner et al. 2006), participant structures or principles (Bereiter and Scardamalia 2008) — and may shed light on CSCL pedagogy.

\section{Technology-supported inquiry and innovation}

How do teachers come together to learn about technology as they engage in innovation? This study highlights the importance of examining technology-enhanced innovation in relation to the complex socio-cultural milieu of the classroom and epistemological issues. At the beginning, many KBTN teachers referred to this ministry-funded project as the Knowledge Forum project. Some teachers held the view that this project was about learning a new piece of technology to help their students to write more. As noted before, in one interview excerpt, one teacher seemed to feel that her students would learn more if she alone learned more about the software. There was a lack of understanding that CSCL research-based innovation required a fundamental change in their beliefs and practices; teachers' understanding of technology and collaboration situated in a socio-cultural milieu needs to be examined to effect classroom innovation.

Research has shown that teachers go through different phases in adopting technology; communities of practice are useful for scaffolding and connecting technology use with principle-based understanding. One approach is to engage teachers in using technology in ways that are aligned with principles, pedagogy, and assessment, thus affording them deeper insights. KBTN teachers were encouraged to contribute to the Forum to help them experience how technological affordances connect with pedagogy. Tool development for the assessment of knowledge building is not just for research analysis; the tools can be placed in the hands of teachers and students so that they might take agency to reflect on their work. A major theme in teacher development is that of helping teachers to focus less on their teaching and more on student thinking; technology can be developed to facilitate such a direction in ways related to a deeper understanding of principles as it relates to teachers' classroom needs. To develop teacher capacity for classroom innovation, teachers need to develop deeper views of the integral relations of principles, pedagogy, and technology.

Classroom innovation as inquiry for knowledge creation

This theme considers re-conceptualizing research and practice gaps when designing CSCL research for educational innovation. A key idea is to examine classroom innovation as an inquiry process across multiple contexts towards the creation of usable knowledge.

\section{Design-based research and hybrid culture}

A common belief is the dichotomy between scientific research and applied research. Methodologically, design-based research has been advanced in the learning sciences to put research into classrooms. In design research, the design and outcomes of each iteration are 
used to identify the refinements needed for the next cycle and to refine theory and design (Collins et al. 2004). KBTN includes multiple groups of teachers with various peripheral and legitimate degrees of participation. Teachers engaged in different forms of design-based research seemed more able to move further in shifts of understanding. The seconded teachers worked together on innovative approaches to improve assessment designs; responses to these approaches were used to improve subsequent designs. In the case of $\mathrm{Mr}$ K, his classroom design was developed over years with progressive approximation as he worked towards the goal of designing assessments to foster collaboration. Examples of new teachers engaging in design-based research provide other information illustrating the problems facing new teachers as they learn new CSCL-based pedagogy. The problems, hurdles, "misconceptions," and slow changes through the design as inquiry process help to illuminate that CSCL-based pedagogy is more than a simple intervention but requires an analysis of socio-cultural aspects and changes in classroom culture. Design-based research is apparently an important methodology linking research and practice, but it is also complex and resource-intensive, and questions have been raised about the different ways to examine design-based research (Krange and Ludvigsen 2009). It would be fruitful to examine different approaches to design-based research and how it might be best conducted.

Design-based research helps to bridge the chasm between teachers and researchers. Bereiter (2002) postulates the notion of a hybrid culture in which teachers and researchers work together-it is not necessary that researchers become teachers or vice versa, just that they work jointly and that each uses his or her expertise to tackle the common problems. For example, KBTN researchers are interested in theories and analytical schemes related to collaborative discourse, and teachers are interested in helping students produce better writing. The common problem, at a deeper level, is how to characterize knowledge building and how to scaffold students towards a more productive knowledge creation discourse. CSCL tools and analysis schemes developed by researchers could be considered from a teacher perspective, while teachers could provide insightful information on how discourse is created in the social milieu. The discourse scheme that was developed based on KBTN work (Table 3) provided an overview of teachers' databases and opened up possibilities for further research into discourse moves. The key lesson is that researchers do not just ask schools and teachers to adopt pedagogy developed in other classrooms; they work together with teachers to create new usable knowledge. Co-inquiry and knowledge creation-not the imposition of ready-made innovation-is a key theme in designing and facilitating collaboration in professional communities.

\section{Classroom innovation as a process of inquiry}

Goldman (2005) discusses educational innovation as a process of inquiry into practice. When innovation is a process of inquiry, effectiveness at different levels needs to be coordinated (Means and Penuel 2005); for example, micro-level student interactions within the classroom learning environments need to be examined for classroom improvement, with the results fed back to the teacher network and evaluations informing the macro-context of the system. In particular, student growth must be a focal point, and teacher development must be grounded in student work. With a focus on innovation as inquiry, KBTN teachers and researchers work jointly using data on students' forum participation to understand more about student participation modes and discourse patterns; these analyses provide useful feedback for ongoing improvement of classroom design as well as design for teacher professional development. Teachers' understanding is examined to understand how their epistemology influences student collaboration. Teacher change is examined in relation to 
changes in student participation and case studies of teacher growth are conducted to examine how teachers engage in principle-based understanding, make epistemological changes, and move towards more collaborative pedagogy.

While a design-based approach is useful for micro-level classroom research, CSCL in classrooms also provides opportunities for diverse methodological approaches that can be examined at multiple levels. CSCL researchers and teachers may work together to advance different research goals in synergistic ways. KBTN provides a rich test-bed for CSCL inquiry, methodologies, experiments, and discourse analyses - the wide range of collaborative discourse contained in the multiple Knowledge Forum databases, for example, provide a rich data corpus for research analyses and advances. Examining and inquiring into the processes of innovation at different levels is challenging but may enrich research methodology and create new and usable knowledge.

\section{Conclusions}

Researchers lament that there is limited impact of research on educational practice. This paper examined the problem of how CSCL research may be integrated into classroom systems in the context of implementing knowledge-building innovation in Hong Kong. The case study in Hong Kong illustrates how the macro context of educational reform can bring about meso-level changes in the emergence of a teacher network to support innovation and how the research-based innovation can be practiced in the classroom when the teacher aligns the model with the socio-cognitive and social-cultural underpinning of the classroom.

CSCL for educational reform involves more than designing the best tools or providing CSCL technology for teachers and students; it involves complex and emergent changes that need to be coordinated across different levels. This account suggests that political forces, social mechanisms, cultural influences, technology use, and socio-cognitive dynamics interact in different ways, impacting innovation. It is important to address macro-level political considerations while developing meso-level enabling structures and aligning them with micro-level classroom changes. In particular, a teacher network may provide a mesolevel structure that coordinates and regulates macro-level political, institutional, and cultural influences on micro-level classroom processes and student change. There are also lessons learned relating to building capacity in order to forge a hybrid culture to transcend gaps for community building. This paper also considered teacher development as knowledge creation, with teachers working collectively to build knowledge. Integration of new pedagogy and technology into the classroom needs to be considered in relation to sociocultural-historical and epistemological aspects of classroom life; principle-based understanding is important for innovation to sustain. Various examples have been provided as to how CSCL classroom innovation draws upon theoretical ideas while simultaneously inspiring research and analyses such as characterizing knowledge-building discourse and suggesting new ways of considering CSCL assessment and tools.

The contribution of this paper has been to highlight issues, questions, and possibilities, which can open up a discussion on how CSCL research may be examined in classroom and school systems for educational impact. It may be interesting to consider how lab-based studies of collaboration may be examined in classrooms; for example, researchers have now examined micro and macro-scripting and educational perspectives (see Fischer et al. 2007; Hakkinen and Makitalo-Siegl, 2007). Examining classroom innovation may shed light on the nature, design, and conditions for the emergence of collaboration in complex settings and extend our understanding of how socio-cognitive, cultural, and systemic forces impinge 
on collaboration. The contrast of principle-based versus activity-based approaches (Scardamalia and Bereiter 2006) and guided instruction versus emergent inquiry (HmeloSilver et al. 2007; Kirschner et al. 2006) raises many theoretical issues of design of CSCL pedagogy and is in need of further exploration. Examining CSCL in classrooms suggests analyses to examine discourse beyond the small-group level to the discourse created in classroom communities. How CSCL technology can be developed for both formative and summative assessment, and for both examining and scaffolding collaboration, would be additional fruitful questions. Designing collaboration for classroom practice calls for further inquiry into how design-based research works, as well as for the development of a wider range of research methodology and analyses from different paradigms.

Since this paper is written to explore a range of issues about how CSCL research may be integrated into classroom practice, it has not focused on the details of data analyses and many areas have been only briefly examined. The teacher network is one possible way to spread classroom innovation; this paper has considered some of the challenges of scaling associated with this approach. The experience of implementing knowledge building in Hong Kong classrooms provides an actual example of how various parties can work together to create possibilities that take into consideration the macro, meso, and micro levels with emergent changes for sustained growth. Examining how collaboration and innovation may be designed and facilitated in complex settings over prolonged periods may help to address knowledge creation needed for the twenty-first century. While the examples are drawn from Hong Kong classrooms, the issues and questions are relevant to other communities and can, hopefully, enrich our understanding of how to synergize policy, research, and practice in CSCL. Diverse CSCL research can inform school practice significantly, while examining CSCL in classrooms may raise new theoretical questions on how collective knowledge creation may emerge in knowledge communities.

Acknowledgements The project reported in this paper is supported by research and development funds from The School-University Partnership Funding Scheme, (Education Bureau), the General Research Funds (\#740809H, University Grants Council), and the Strategic Research Theme Sciences of Learning (University of Hong Kong). The author would like to thank Nancy Law and Jan van Aalst for the useful discussion and stimulating ideas for the design of the project and writing of the manuscript. Many thanks are due to the principals, seconded teachers, teacher associates, network teachers of the participating schools, and particularly to Nancy Law and her technical team at The Centre for Information and Technology for their collaboration and support.

Open Access This article is distributed under the terms of the Creative Commons Attribution Noncommercial License which permits any noncommercial use, distribution, and reproduction in any medium, provided the original author(s) and source are credited.

\section{References}

Arnseth, H. C., \& Ludvigsen, S. (2006). Appropriating institutional contexts: Systemic versus dialogic research in CSCL. International Journal of Computer-Supported Collaborative Learning, 1(2), 167-185.

Barab, S. A., \& Luehmann, A. L. (2003). Building sustainable science curriculum: Acknowledging and accommodating local adaptation. Science Education, 2003(4), 454-467.

Bereiter, C. (2002). Education and mind in the knowledge age. Mahwah: Erlbaum.

Bereiter, C., \& Scardamalia, M. (2008). Toward research-based innovation. In Innovating to learn, learning to innovate (pp. 67-87). Centre for Educational Research and Innovation, Organization for Economic Cooperation and Development.

Bielaczyc, K. (2006). Designing social infrastructure: Critical issues in creating learning environments with technology. The Journal of the Learning Sciences, 15(3), 301-329. 
Brown, A. L., \& Campione, J. (1996). Psychological theory and the design of innovative learning environments: On procedures, principles and systems. In L. Schauble \& R. Glaser (Eds.), Innovations in learning: New environment for education (pp. 289-325). Mahwah: Erlbaum.

Chan, C. K. K. (2008). Pedagogical transformation and knowledge building for the Chinese learner. Evaluation and Research in Education, 21(3), 235-251.

Chan, C. K. K. \& Chan, Y. Y. (2011). Student views of collaboration and online participation in Knowledge Forum. Computers \& Education 57(1), 1445-1457.

Chan, C. K. K. \& Fu, E. L. F. (2011 July). Principle-based design for collective growth: From knowledgesharing to explanatory knowledge-building discourse. Conference proceeding paper presented at the International Conference of Computer-Supported Collaborative Learning, Hong Kong.

Chan, C. K. K., \& Lam, C. K. (2010 June). Conceptual change and epistemic growth through reflective assessment in computer-supported knowledge building. Conference proceeding paper presented at the International Conference of Learning Sciences, Chicago.

Chan, C. K. K., Law, N., \& van Aalst, J. (2008 April). Developing principle-based understanding for knowledge building in a teacher community. Paper presented at the Annual Meeting of the American Educational Research Association, New York.

Collins, A., Joseph, D., \& Bielaczyc, K. (2004). Design research: Theoretical and methodological issues. Journal of the Learning Sciences, 13(1), 15-42.

Cuban, L. (1986). Teachers and machines: The classroom use of technology since 1920. New York: Teachers College Press.

Cuban, L., Kirkpatrick, H., \& Peck, C. (2001). High access and low use of technologies in high school classrooms: Explaining an apparent paradox. American Educational Research Journal, 38(4), 813-834.

Dede, C. (2006). Evolving innovations beyond ideal settings to challenging contexts of practice. In K. Sawyer (Ed.), The Cambridge handbook of the learning sciences (pp. 551-566). New York: Cambridge University Press.

Dede, C., \& Honan, J. P. (2005). Scaling up success: A synthesis of themes and insights. In C. Dede, J. P. Honan, \& L. C. Peters (Eds.), Lessons learned from technology-based educational innovation (pp. 227239). San Francisco: Jossey-Bass.

Dillenbourg, P. (2004). Over-scripting CSCL: The risks of blending collaborative learning with instructional design. In P. A. Kirschner (Ed.), Three worlds of CSCL: Can we support CSCL? (pp. 61-91). Open Universiteit Nederland: Heerlen.

Dillenbourg, P., Jarvela, S., \& Fischer, F. (2009). The evolution of research on computer-supported collaborative learning: From design to orchestration. Technology-Enhanced Learning, 1, 3-19.

Doyle, W. (1992). Curriculum and pedagogy. In P. W. Jackson (Ed.), Handbook of research on curriculum (pp. 486-516). New York: Macmillan.

Engeström, Y., Engeström, R., \& Suntio, A. (2002). Can a school community learn to master its own future? An activity - theoretical study of expansive learning among middle school teachers. In G. Wells \& G. Claxton (Eds.) Learning for life in the 21st century.

Fischer, F., Kollar, I., Mandl, H., \& Haake, J. M. (Eds.). (2007). Scripting computer-supported collaborative learning: Cognitive, computational and educational perspectives. New York: Springer.

Fishman, B., Marx, R. W., Blumenfeld, P., \& Krajcik, J. (2004). Creating a framework for research on systemic technology innovations. The Journal of the Learning Sciences, 13(1), 43-76.

Goldman, S. (2005). Designing for scalable educational improvement: Processes of inquiry in practice. In C. Dede, J. P. Honan, \& L. C. Peters (Eds.), Scaling up success: Lessons learned from technology-based educational improvement (pp.67-96). San Francisco: Jossey-Bass.

Hakkarainen, K. (2002). Emergence of progressive-inquiry culture in computer-supported collaborative learning. Learning Environments Research, 6(2), 199-220.

Hakkarainen, K. (2009). A knowledge-practice perspective on technology-mediated learning. International Journal of Computer-Supported Collaborative Learning, 4(2), 213-231.

Hakkinen, P., \& Makitalo-Siegl, K. (2007). Educational perspectives in scripting CSCL. In F. Fischer, I. Kollar, H. Mandl, \& J. M. Haake (Eds.), Scripting computer-supported collaborative learning: Cognitive, computational and educational perspectives (pp. 263-274). New York: Springer.

Hmelo-Silver, C., Duncan, R. G., \& Chinn, C. A. (2007). Scaffolding and achievement in problem-based and inquiry learning: A response to Kirschner, Sweller, and Clark (2006). Educational Psychologist, 42, 99-107.

Hong, H. Y., Scardamalia, M., \& Zhang, J. W. (2010). Knowledge Society Network: Toward a dynamic, sustained network for building knowledge. Canadian Journal of Learning and Technology, 36 (1).

Jones, C., Dirckinck-Holmfeld, L., \& Lindström, B. (2006). A relational, indirect, meso-level approach to CSCL designin thenextdecade. International Journal of Computer-Supported Collaborative Learning, 1(1), 35-56.

Kirschner, P. A., Sweller, J., \& Clark, R. E. (2006). Why minimal guidance during instruction does not work: An analysis of the failure of constructivist, discovery, problem-based, experiential, and inquiry-based teaching. Educational Psychologist, 41(2), 75-86. 
Koschman, T., Hall, R., \& Miyake, N. (2002). CSCL2: Carrying forward the conversation. Mahwah: Erlbaum.

Krange, I., \& Ludvigsen, S. (2009). The historical and situated nature of design experiments-Implications for data analysis. Journal of Computer-Assisted Learning, 25(3), 268-279.

Laferrière, T., \& Law, N. (2010). Knowledge building international project (KBIP): A nested network of learning and knowledge creation. Conference proceeding paper presented at the International Conference of Learning Sciences, Chicago.

Laferrière, T., Erickson, G., \& Breuleux, A. (2007). Innovative models of web-supported university-school partnerships. Canadian Journal of Education, 30(1), 211-238.

Lai, M., \& Law, N. (2006). Peer scaffolding of knowledge building through collaborative groups with differential learning experiences. Journal of Educational Computing Research, 35, 123-144.

Law, N., Pelgrum, W. J., \& Plomp, T. (Eds.). (2008). Pedagogy and ICT in schools around the world: Findings from the SITES 2006 study. Hong Kong: CERC.

Lee, E. Y. C., Chan, C. K. K., \& van Aalst, J. (2006). Students assessing their own collaborative knowledge building. International Journal of Computer-Supported Collaborative Learning, 1, 277-307.

Lemke, J. L., \& Sabelli, N. H. (2008). Complex systems and educational change: Towards a new research agenda. Educational Philosophy and Theory, 40(1), 118-129.

Looi, C. K., So, H. J., Toh, Y., \& Chen, W. (2011). The Singapore experience: Synergy of national policy, classroom practice and design research. International Journal of Computer Supported Collaborative Learning, 6(1), 9-38.

Means, B., \& Penuel, W. R. (2005). Scaling up technology-based educational innovations. In C. Dede, J. P. Honan, \& L. C. Peters (Eds.), Scaling up success: Lessons learned from technology-based educational improvement (pp. 176-197). San Francisco: Jossey-Bass.

Paavola, S., Lipponen, L., \& Hakkarainen, K. (2004). Models of innovative knowledge communities and three metaphors of learning. Review of Educational Research, 74(4), 557-576.

Rasmussen, I., \& Ludvigsen, S. (2009). The hedgehog and the fox: A discussion on the approaches to the analysis of ICT reforms in teacher education of Larry Cuban and Yrjö Engeström. Mind, Culture and Activity, 16, 83-104.

Resnick, L. B. (2010). Nested learning systems for the thinking curriculum. Educational Researcher, 39(3), $183-197$.

Roschelle, J., Tatar, D., Shechtman, N., \& Knudsen, J. (2008). The role of scaling up research and designing for and evaluating robustness. Educational Studies in Mathematics, 68, 149-170.

Sabelli, N., \& Dede, C. (2000). Integrating educational research and practice: Reconceptualizing the goals and process of research to improve educational practice. Retrieved from http://www.virtual.gmu.edu/ SS_research/cdpapers/policy.pdf

Salomon, G. (Ed.). (1997). Distributed cognition: Psychological and educational consideration. Mahwah: Erlbaum.

Scardamalia, M. (2002). Collective cognitive responsibility for the advancement of knowledge. In B. Smith (Ed.), Liberal Education in a Knowledge Society (pp. 67-98). Chicago: Open Court.

Scardamalia, M. (Ed.). (2010). Knowledge building [special issue]. Canadian Journal of Learning and Technology. 36 (1).

Scardamalia, M., \& Bereiter, C. (1994). Computer support for knowledge-building communities. The Journal of the Learning Sciences, 3, 265-283.

Scardamalia, M., \& Bereiter, C. (2006). Knowledge building: Theory, pedagogy, and technology. In R. K. Sawyer (Ed.), The Cambridge handbook of the learning sciences (pp. 97-115). New York: Cambridge University Press.

Schoenfeld, A. H. (2006). Notes on the educational steeplechase: Hurdles and jumps in the development of research-based mathematics instruction. In Constas MA \& Sternberg RJ (Eds.), Translating theory and research into educational practice (pp. 9-30). Mahwah: Erlbaum.

Sfard, A. (1998). On two metaphors for learning and on the dangers of choosing just one. Educational Researcher, 27(2), 4-13.

Stahl, G. (2006). Group cognition: Computer support for building collaborative knowledge. Cambridge: MIT.

Stahl, G., \& Hesse, F. (2010). The CSCL field matures. International Journal of Computer-Supported Collaborative Learning, 5(1), 1-3.

Stahl, G., Koschmann, T., \& Suthers, D. (2006). Computer-supported collaborative learning: An historical perspective. In R. K. Sawyer (Ed.), Cambridge handbook of the learning sciences (pp. 409-426). Cambridge: Cambridge University Press.

Stokes, D. E. (1997). Pasteur's Quadrant: Basic science and technological innovation. Washington: Brookings. 
van Aalst, J. (2009). Distinguishing knowledge-sharing, knowledge-construction, and knowledge-creation discourses. International Journal of Computer-Supported Collaborative Learning, 4(2), 259-287.

van Aalst, J., \& Chan, C. K. K. (2007). Student-directed assessment of knowledge building using electronic portfolios. Journal of the Learning Sciences, 16(2), 175-220.

van Aalst, J., \& Truong, M. S. (2010). Promoting knowledge-building discourse in an Asian primary five classrooms; Results from an inquiry into life cycles. International Journal of Science Education, 33(4), 487-515.

Watkins, D. A., \& Biggs, J. B. (Eds.). (1996). The Chinese learner: Cultural, psychological and contextual influences. Melbourne/Hong Kong: Australian Council for Educational Research/Comparative Education Research Centre, University of Hong Kong.

Wiske, M. S., \& Perkins, D. (2005). Dewey goes digital: Scaling up constructivist pedagogies and the promise of new technologies. In C. Dede, J. P. Honan, \& L. C. Peters (Eds.), Scaling up success: Lessons learned from technology-enhanced educational improvement (pp. 27-47). San Francisco: Jossey-Boss.

Zhang, J. (2010). Technology-supported learning innovation in cultural context. Educational Technology and Research Development, 58(2), 229-242.

Zhang, J., Scardamalia, M., Reeve, R., \& Messina, R. (2009). Designs for collective cognitive responsibility in knowledge-building communities. Journal of the Learning Sciences, 18(1), 7-44.

Zhang, J., Hong, H. Y., Scardamalia, M., Teo, C.L., \& Morley, E. (2011). Sustaining knowledge building as a principle-based innovation at an elementary school. Journal of the Learning Sciences, 20(2), 262-307. 